\title{
Priming of mental operations by masked stimuli
}

\author{
UWE MATTLER \\ Technische Universität Braunschweig, Braunschweig, Germany
}

\begin{abstract}
Motor responses can be affected by visual stimuli that have been made invisible by masking. Can masked visual stimuli also affect nonmotor operations that are necessary to perform the task? Here, I report priming effects of masked stimuli on operations that were cued by masking stimuli. Cues informed participants about operations that had to be executed with a forthcoming target stimulus. In five experiments, cues indicated (1) the required response, (2) part of the motor response, (3) the stimulus modality of the target stimulus, or (4) the task to be performed on a multidimensional stimulus. Motor and nonmotor priming effects followed comparable time courses, which differed from those of prime recognition. Experiment 5 demonstrated nonmotor priming without prime awareness. Results suggest that motor and nonmotor operations are similarly affected by masked stimuli.
\end{abstract}

Motor responses can be affected by visual stimuli that have been made invisible by masking. For example, Fehrer and Raab (1962) presented a square that was followed by two flanking squares after varying stimulus onset asynchronies (SOAs). When participants were to respond as soon as a stimulus appeared, simple reaction time (RT) was virtually independent of SOA, although verbal reports of stimulus visibility changed with variations in SOA (see Neumann \& Klotz, 1994). This dissociation has been confirmed and extended by recent work that has also employed metacontrast masking to manipulate stimulus visibility. In metacontrast masking, the visibility of a briefly flashed prime stimulus is reduced by a subsequent spatially flanking masking stimulus (Breitmeyer, 1984). Wolff (1989) and Neumann and Klotz found that choice RTs to the mask are shortened or inhibited if primes share stimulus attributes with masks that are critical for the correct or the alternative response, respectively (see Klotz \& Neumann, 1999). Electrophysiological evidence from event-related potentials measured over the motor cortex suggests that stimuli made invisible by masking can activate specific responses at the motor cortex (Dehaene et al., 1998; Eimer \& Schlaghecken, 1998; Leuthold \& Kopp, 1998).

Do masked stimuli affect the motor system because of direct visuomotor effects, as has been suggested by Neumann and Klotz (1994; see Eimer \& Schlaghecken, 1998; Leuthold \& Kopp, 1998), or do these priming effects show that "a large amount of cerebral processing

A preliminary report of the data was given at the Conference of Cognitive Neuroscience in Bremen (Germany), November 1999. I thank Hannes Schröter for helping in data collection, Armin Heinecke and Jens Schwarzbach for helpful discussions, and Dirk Vorberg for supportive comments throughout the work and on an earlier draft of the manuscript. Correspondence concerning this article should be addressed to U. Mattler, Institut für Psychologie, Technische Universität Braunschweig, Spielmannstr. 19, 38106 Braunschweig, Germany (e-mail: u.mattler@tu-bs.de). including perception, semantic categorization and task execution, can be performed in the absence of consciousness," as has been claimed by Dehaene et al. (1998, p. 599)? According to the first view, priming without awareness is possible because the motor system can be affected by visual information, owing to a special anatomical connection, most probably the dorsal pathway, which connects the visual cortex to the motor system (Milner \& Goodale, 1995). According to this, there is a special pathway from the visual system to the motor system, and thus, priming without awareness might be restricted to conditions in which primes can be mapped directly to motor responses.

Interestingly, direct mapping of primes to motor responses might have occurred in previous studies on nonmotor priming effects (e.g., Dehaene et al., 1998; Greenwald, Draine, \& Abrams, 1996), as has been suggested by recent findings (Abrams \& Greenwald, 2000; Klinger, Burton, \& Pitts, 2000; Wentura, 2000). For instance, in the experiment of Dehaene and colleagues, participants had to categorize four stimuli to one response and four to another. After sufficient training, the participants might have learned simple stimulus-response associations. These associations may no longer have required semantic categorization of stimuli but may have allowed primes to affect motor responses directly via the dorsal pathway. Thus, the data of Dehaene and colleagues do not convincingly show that perceptual and semantic processes occur without awareness. Only the recent analyses and experiments of Naccache and Dehaene (2001a, 2001b) provide evidence for semantic effects of primes.

In the present study, I investigated whether the effects of masked stimuli are restricted to motor effects, or whether masked stimuli can similarly affect nonmotor operations, such as attention and cognitive control. To compare nonmotor priming with motor priming, the time course of priming was examined by varying the time between prime and masking stimuli. Then, the dissociation of priming and prime recognition was examined by comparing the time course of priming with the time course of 
prime recognition. With this paradigm, an attempt was made to find a double dissociation, consisting of a time course for increasing priming effects and a time course for decreasing prime visibility. It was reasoned that if masked stimuli affect motor and nonmotor operations in the same way, the same double dissociation of priming and prime recognition should be obtained in either case. The first experiment replicated previous studies in which participants responded to the mask with a choice response. In the following experiments, the mask was used as a cue that provided information obligatory for performing the task. In Experiment 2, the cue provided partial information about the forthcoming response, and priming effects on partial response preparation were examined. Nonmotor priming was examined in the following three experiments. In Experiment 3, the cue provided information about stimulus modality. In Experiments 4 and 5, the cue told participants how they had to process the following multidimensional auditory sound. The last three experiments were designed to exclude motor priming effects. In these experiments, the priming of nonmotor operations necessary to execute a task without any possible effects of primes on the motor system was studied.

The present study contrasted prime recognition performance with motor and nonmotor priming effects by showing double dissociation in terms of opposite time courses. In previous studies, attempts had been made to show priming without awareness by perfectly masking the prime stimulus (e.g., Klotz \& Neumann, 1999; Leuthold \& Kopp, 1998). These studies were in line with traditional research on "perception without awareness" that sought to demonstrate behavioral effects of stimuli of which we are not aware (see Greenwald, 1992; Köhler \& Moscovitch, 1997). However, the reality of "unconscious perception" remains controversial up to the present (e.g., Eriksen, 1960; Greenwald, 1992; Holender, 1986; Merikle, 1992; Merikle \& Daneman, 1998; Reingold \& Merikle, 1990). Therefore, it is important to distinguish empirical findings from controversial issues of interpretations. In this paper, I use the term priming to refer to empirical effects of masked stimuli on the motor system or on other operations, as assessed by RT and error rate. Another empirical effect of masked stimuli is referred to by the term prime recognition, which is measured by two-choice recognition judgments to the masked stimuli. Prime recognition performance is one attempt to operationalize conscious perception of the prime. Unfortunately, it is still not clear how performance in a prime recognition task is related to conscious perception. Note, however, that this controversial issue refers to any claim of priming without awareness and is not specifically related to the comparison of motor and nonmotor priming. Therefore, the issue of conscious awareness can be separated from the dissociation of priming and prime recognition performance in motor and nonmotor priming tasks (see the General Discussion section).

\section{EXPERIMENT 1 Priming of Motor Responses}

To study dissociations between response priming and prime recognition, I compared the performances on two tasks that differed only by which stimulus served as target but left stimulus conditions identical. On each trial, a prime was presented briefly, followed after a variable SOA by a mask at the same location. This paradigm allows one to study the dissociation of priming and prime recognition by their time courses (see Vorberg, Mattler, Heinecke, Schmidt, \& Schwarzbach, in press). The time course of response priming was studied by using a choice-reaction task in which subjects had to respond to the mask. The effect of masked primes was assessed by the effects of prime-mask congruence on RT. Prime and mask stimuli were congruent when they had the same outer shape and were incongruent otherwise (see Figure 1). Priming was assessed by comparing the RT advantage on congruent trials, with those on incongruent trials. The time course of priming was determined by the extent of priming at different SOAs. The time course of prime recognition was studied in a two-choice prime recognition task in which subjects were asked to respond to the prime. The time course of prime recognition was determined by measuring prime recognition at different

\section{Congruent}
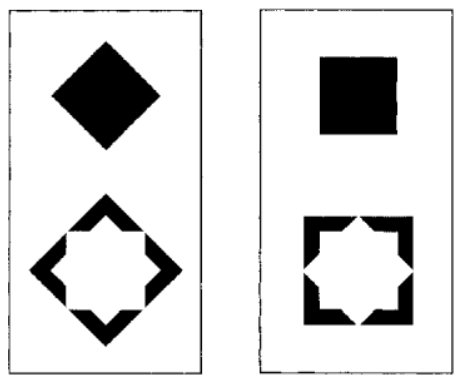

Incongruent

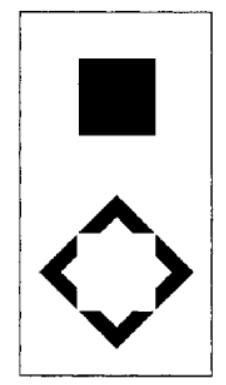

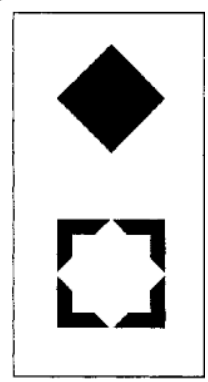

Figure 1. Stimuli used for metacontrast masking in Experiments 1-4. On half the trials, primes were congruent to masks. Note that one prime-mask pair was presented in each trial. 
SOAs. Prime and masking stimuli were constructed to obtain Type $B$ metacontrast masking functions (Breitmeyer, 1984), partly consisting of decreasing prime recognition performance with increasing SOA. It was expected that priming and prime recognition would follow different time courses, constituting a double dissociation of priming and prime recognition.

\section{Method}

Participants. Six students from the University of Braunschweig ( 5 women, $1 \mathrm{man}$ ), from 20 to 28 years of age $(M=23.0$ years), participated in the experiment. All reported that they were righthanded, and all had normal or corrected-to-normal vision. Each participant took part in three 1 -h sessions, receiving course credit for participation.

Stimuli. Stimuli similar to those introduced by Neumann and Klotz (1994) were used. Square and diamond shaped stimuli served as prime and mask stimuli (see Figure 1). They were presented black on white on a computer monitor, at a refresh rate of $60 \mathrm{~Hz}$. The stimuli were positioned at the fixation cross in the center of the monitor. Squares and diamonds consisted of the same number of pixels. Prime squares and diamonds subtended visual angles of about $1.0^{\circ}$ and $1.5^{\circ}$ in height and width. The height and width of the outer contour of the masks subtended about $1.6^{\circ}$ and $2.2^{\circ}$ of visual angle for square and diamond-shaped masks, respectively. The primes were 1 pixel smaller than the inner outline of the masks. Prime duration was $34 \mathrm{msec}$; mask duration was $51 \mathrm{msec}$. Primemask SOA varied randomly from trial to trial, in steps of $17 \mathrm{msec}$, from 34 to $119 \mathrm{msec}$. The primes were congruent with the masks in half of the trials, with congruency varying randomly between trials. Visual and auditory stimuli were presented $102 \mathrm{msec}$ after mask offset for $102 \mathrm{msec}$; these were irrelevant for the task in Experiment 1 but were relevant in Experiment 3 (see below). Thus, these stimuli served as distractors in Experiment 1 (see Figure 2). An auditory stimulus of $1000 \mathrm{~Hz}$ and $100-\mathrm{msec}$ duration served as error feedback.

Tasks. (1) In the choice RT task, the participants responded to diamond-shaped (square) mask stimuli by pressing the left (right) ALT key on the keyboard with the left (right) index finger. (2) In the last session, the participants were informed about the presence of primes and were to respond to the shape of the primes without pres-

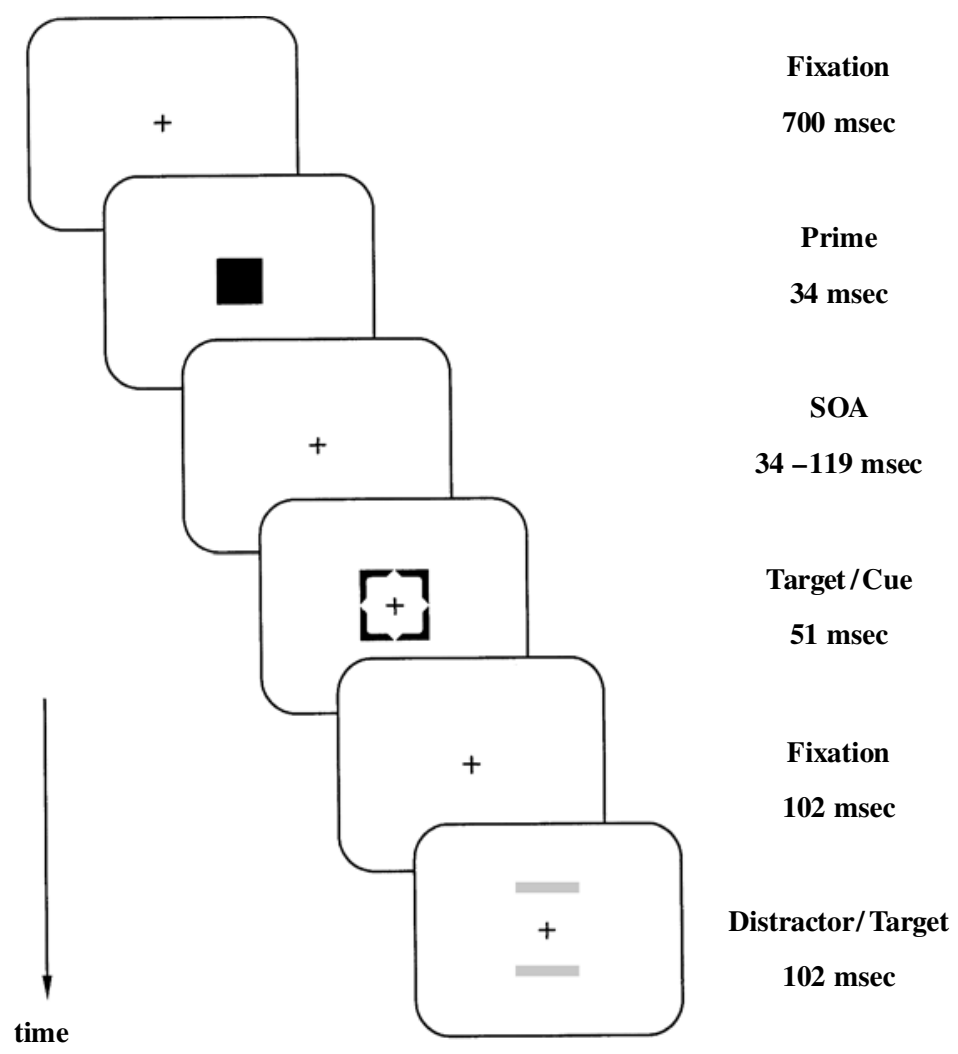

Figure 2. Schematic diagram of stimulus events in Experiments 1-4. In the choice reaction time (RT) task, the participants used the mask as a target in Experiment 1, but as a cue in Experiments 2-4. The stimulus presented after the mask was irrelevant in Experiment 1 but was used as the target in later experiments. Priming effects were assessed by the effects of prime-mask congruency on RT. In the prime recognition task, the participants reported the prime. Time courses of priming and prime recognition were assessed by varying stimulus onset asynch rony (SOA) between prime and mask randomly from trial to trial. Note that the bars in the last frame were either green or red. Experiment 3 used the color bars and tones as targets in the choice RT task. Experiment 4 used no color bars at all but presented sounds via headphones as targets in the choice RT task. 
sure with respect to speed: They responded to a diamond-shaped (square) prime stimulus with a left- (right-) hand response. ${ }^{1}$

Procedure. The participants were tested individually in single sessions on separate days. (1) In the choice RT task, the participants were instructed to focus on the fixation stimulus and to respond to the stimulus in the center of the screen as quickly as possible, without making errors. The stimulus sequence is given in Figure 2. Trials started with the fixation cross, followed after $700 \mathrm{msec}$ by the prime positioned at fixation and the mask at the same position. Responses were given by pressing the appropriate response button with the left or the right index finger. The computer monitored for responses made within 2,150 msec after mask onset. In case of a wrong response, auditory feedback was given after this period, followed by a rest of $2 \mathrm{sec}$. The warning signal for the next trial appeared after a random interval with a mean $1,500 \mathrm{msec}$. (2) At the beginning of the session with the direct prime recognition task, the prime and the mask stimuli were shown to the participants in slow motion. They were instructed to take all the time needed in order to identify the primes as accurately as possible. The computer monitored for responses made within $6 \mathrm{sec}$ after mask onset. In either task, auditory feedback was provided on error trials. Summary feedback (mean RT and percentage correct) was given at the end of each session.

Design. Perceptual and behavioral effects of the prime stimuli were assessed by the two tasks. The choice RT task, which employed the mask as the target for a speeded choice response, was used to measure the effect of primes on RT to the mask by comparing mean RTs of congruent and incongruent trials. The two-choice prime recognition task, which employed the prime as the target, was used to measure how well the participants could recognize the primes. A practice session was followed by another session with the choice RT task and by the final session with the prime recognition task, each task consisting of 48 replications of each of the 12 conditions resulting from the combination of SOA (six levels) and congruency (two levels). All combinations were presented in random order. Dependent variables were RT and error rates for the choice RT task and proportion correct for the prime recognition task.

Statistical analysis. The first blocks per session were considered warm-up and were excluded from data analysis. Choice RTs were summarized by trimmed means, determined for correct trials per participant and condition, excluding posterror trials. RTs and error rates for the choice RT task were analyzed with a two-way repeated measures analysis of variance (ANOVA). Prime recognition performance was analyzed with an ANOVA with a factor of SOA on the arc-sine transformed mean proportion correct, determined separately for each participant and mask and then averaged for each SOA condition. For the sake of readability, the results of the statistical analysis of proportion correct are presented, although analysis with signal detection methods (Macmillan \& Creelman, 1991) gave essentially the same results. Table 1 presents summary results for $d^{\prime}$ and beta from a signal detection analysis. All reported $p$ values are based on GeisserGreenhouse corrected degrees of freedom, whereas, for the sake of readability, the stated degrees of freedom are uncorrected. Statistical analysis remained identical across experiments.

\section{Results}

Errors. Errors occurred on $3.7 \%$ of the trials. Mean error rates increased with increases in SOA $(1.7 \%, 0.7 \%$, $1.7 \%, 4.2 \%, 5.4 \%$, and $8.2 \%$ for each SOA, respectively). This was confirmed by an ANOVA on arc-sine transformed choice error rates that showed a significant effect of SOA $\left[F(5,25)=6.93, M S_{\mathrm{e}}=0.029, p<.05\right]$. Mean error rates are given in Table 2.

RT. Primes affected RT significantly, as is shown by the significant effect of congruency, with 420 and $484 \mathrm{msec}$ for congruent and incongruent trials, respec-
Table 1

Results of Signal Detection Analysis

\begin{tabular}{lcccccc}
\hline & \multicolumn{7}{c}{ SOA (msec) } \\
\cline { 2 - 7 } Measure & 34 & 51 & 68 & 85 & 102 & 119 \\
\hline \multicolumn{7}{c}{ Experiment 1 } \\
$d^{\prime}$ & 1.92 & 1.58 & 0.62 & 0.42 & 0.75 & 0.91 \\
beta & 2.38 & 2.75 & 1.53 & 1.36 & 2.12 & 1.75 \\
\multicolumn{7}{c}{ Experiment 2 } \\
$d^{\prime}$ & 0.85 & 0.55 & 0.77 & 0.93 & 0.97 & 1.13 \\
beta & 1.15 & 0.95 & 0.93 & 1.32 & 0.97 & 0.92 \\
\multicolumn{7}{c}{ Experiment 3 } \\
$d^{\prime}$ & 0.76 & 1.34 & 0.89 & 1.00 & 1.05 & 1.24 \\
beta & 1.22 & 2.23 & 1.03 & 1.61 & 1.89 & 1.52 \\
\multicolumn{7}{c}{ Experiment 4 } \\
$d^{\prime}$ & 2.81 & 1.29 & 0.61 & 0.60 & 0.66 & 1.00 \\
beta & 3.25 & 1.39 & 1.19 & 1.28 & 1.22 & 1.24 \\
\hline
\end{tabular}

Note-Prime recognition performance was analyzed by signal detection methods. Performance indices were first estimated separately for each participant and masking stimulus (squares and diamonds). Then, means were determined for each SOA by averaging across participants and masking stimuli.

tively $\left[F(1,5)=17.7, M S_{\mathrm{e}}=4,080, p<.01\right]$. The congruency effect was modulated by $S O A$, as is shown in Figure 3A: Mean RT for congruent trials decreased with increases in SOA, whereas RT for incongruent trials increased. To increase power, this effect of SOA was tested by comparing mean RT on the first three levels of SOA with mean RT on the last three levels of SOA for congruent and incongruent trials $\left[F(1,5)=115, M S_{\mathrm{e}}=25\right.$, $p<.001$, and $F(1,5)=7.7, M S_{\mathrm{e}}=375, p<.05$, respectively]. The interaction of SOA and congruency was significant $\left[F(5,25)=29.4, M S_{\mathrm{e}}=150, p<.01\right]$. To evaluate how SOA modulated the effect of congruency, priming functions were defined as the difference in RTs between incongruent and congruent trials. The priming function in Figure 3B shows that the priming effect increased almost linearly with SOA. Note that the slope of the priming function approaches one, which means that increasing SOA by $10 \mathrm{msec}$ resulted in an increase of the priming effect of $10 \mathrm{msec}$.

Prime recognition. Overall, prime recognition responses were correct in $65.5 \%$ of the trials. Proportion correct, given in Figure 3C as a function of SOA, shows that prime recognition depended on SOA $[F(5,25)=5.9$, $\left.M S_{\mathrm{e}}=0.045, p<.05\right]$. Note that the participants recognized primes better at short SOAs than at longer SOAs. This time course of prime recognition corresponds to Type B masking functions (Breitmeyer, 1984).

\section{Discussion}

Experiment 1 provides strong evidence for response priming and demonstrates a double dissociation between priming and prime recognition (compare Figures $3 \mathrm{~B}$ and 3C): RTs to the mask showed priming effects that increased with increases in SOA, whereas prime recognition decreased with increases in SOA. In other words, priming effects increased with increases in SOA, although the 
Table 2

Error Rates (in Percentages)

\begin{tabular}{|c|c|c|c|c|c|c|}
\hline \multirow{2}{*}{$\begin{array}{l}\text { Prime-Mask } \\
\text { Congruency }\end{array}$} & \multicolumn{6}{|c|}{ SOA (msec) } \\
\hline & 34 & 51 & 68 & 85 & 102 & $\overline{119}$ \\
\hline \multicolumn{7}{|c|}{ Experiment 1} \\
\hline Congruent & 2.4 & 0.4 & 0.7 & 1.1 & 1.1 & 1.8 \\
\hline Incongruent & 1.1 & 1.1 & 2.8 & 7.3 & 9.7 & 14.6 \\
\hline \multicolumn{7}{|c|}{ Experiment 2} \\
\hline Congruent & 3.7 & 3.6 & 4.7 & 3.5 & 3.0 & 2.6 \\
\hline Incongruent & 2.6 & 2.6 & 3.1 & 3.8 & 6.4 & 12.7 \\
\hline \multicolumn{7}{|c|}{ Experiment 3} \\
\hline Congruent & 2.3 & 2.6 & 2.2 & 4.4 & 2.9 & 2.2 \\
\hline Incongruent & 2.4 & 1.9 & 3.4 & 5.1 & 4.8 & 6.6 \\
\hline \multicolumn{7}{|c|}{ Experiment 4} \\
\hline Congruent & 4.2 & 5.4 & 5.2 & 5.2 & 4.7 & 4.2 \\
\hline Incongruent & 6.1 & 4.7 & 4.4 & 4.7 & 4.7 & 3.7 \\
\hline
\end{tabular}

Note-SOA $=$ stimulus onset asynchrony between prime and mask onset. See the text for descriptions of the tasks used in the experiments.

visibility of the primes decreased. Because priming effects depend on the congruency between prime and mask, they reflect stimulus-specific influences. This view was supported by an analysis of the errors in the choice RT task (Table 2). On congruent trials, the error rate was below $3 \%$ at any SOA. On incongruent trials, however, error rate increased with increases in SOA to above $14 \%$. Such an error pattern rules out interpretations in terms of fastguessing triggered by the mere detection of the prime (Yellott, 1971). The error pattern conflicts also with the hypothesis that primes facilitate or inhibit only the processing of the mask (Bachmann, 1984; Neumann \& Klotz, 1994). Further evidence against the latter hypothesis comes from the finding that priming effects increased with increases in SOA, whereas prime recognition decreased with increases in SOA, which renders it unlikely that the priming effect is mediated by perceptual effects of the prime. To sum up, priming effects cannot simply be a function of prime recognition but result from processes that are separate from those that determine performance in the prime recognition task.

The data of Experiment 1 are consistent with the view that primes are processed along a visuomotor pathway, irrespective of perceptual awareness. Neumann (1990, p. 212) introduced direct parameter specification as the notion that input information specifies action parameters without giving rise to a corresponding conscious mental representation of the input information. According to this, direct parameter specification is possible if all parameters of the to-be-executed action have been specified when the stimulus appears, except for those few that can be specified by the stimulus itself (Neumann \& Klotz, 1994). This interpretation is supported by recent neurophysiological evidence for prime-related activation of the motor cortex (Dehaene et al., 1998; Leuthold \& Kopp, 1998).

The dissociation of response priming and prime recognition by their time courses replicates findings of Vorberg et al. (in press), who employed arrow-shaped stimuli as primes and masks. These authors showed, in one of their experiments, that priming can increase with increases in SOA in the face of perfect masking. This finding suggests that mechanisms leading to response priming can operate without conscious awareness of the effective stimuli and are distinct from those that underlie subjective experience in prime recognition. Further evidence for this view was provided by a second experiment of Vorberg et al., which used the double-dissociation paradigm showing identical priming functions in experimental conditions in which prime recognition functions either increased or decreased. The authors proposed an accumulator model that provides a quantitative account for these response priming effects on RT and error rate (see Vorberg et al., in press).
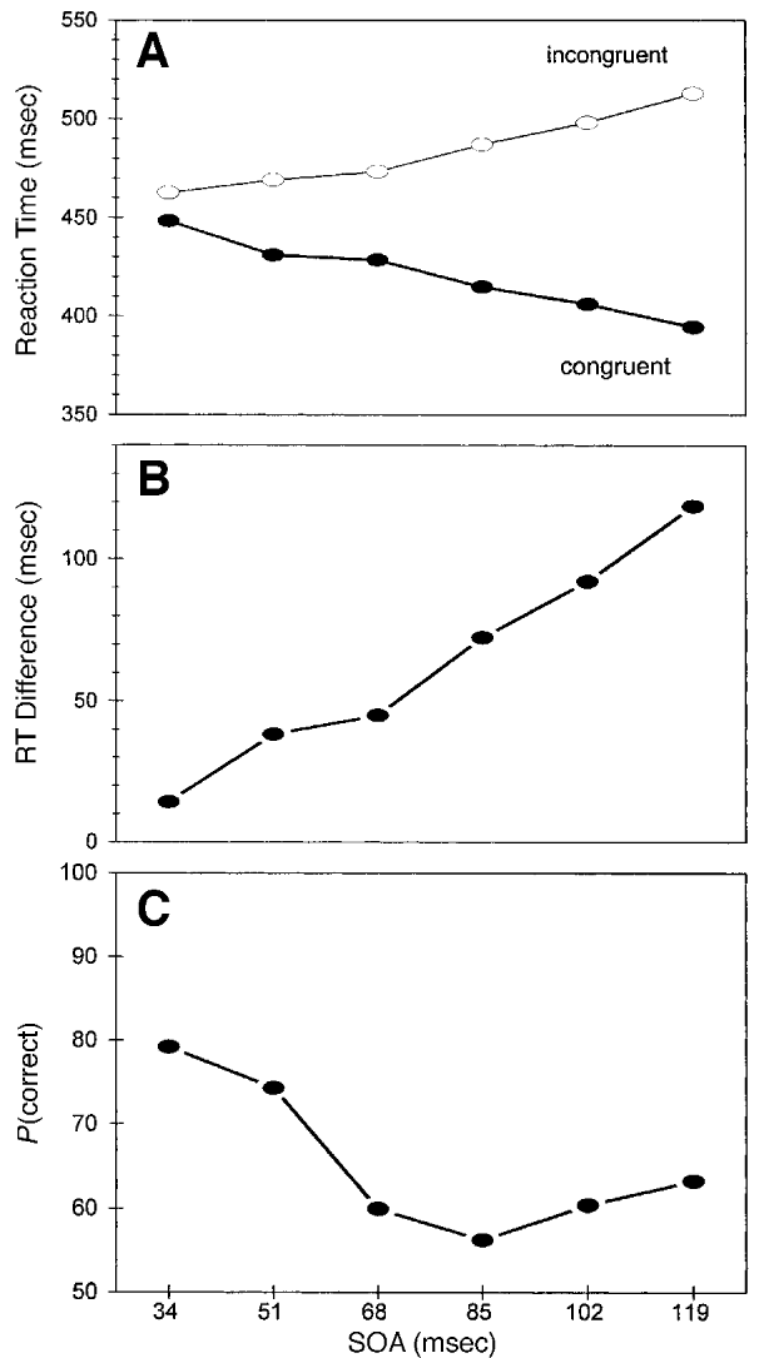

Figure 3. Motor priming and prime recognition as a function of stimulus onset asynchrony (SOA) in Experiment 1. (A) Effects of congruent and incongruent primes on mean choice reaction time (RT). (B) Priming function calculated as the difference between RT on incongruent and congruent trials. (C) Time course of prime recognition: probability of correct prime recognition. 
To sum up, the findings of Experiment 1 replicated those of previous research and documented that motor responses can be activated by masked visual stimuli irrespective of how well the effective stimuli can be reported when target stimuli are associated directly to a motor response. Note that the mask served in Experiment 1 as a target stimulus to which the participants responded directly. In Experiment 2, the mask served as a cue providing information that was obligatory for performing the task. Do priming effects also occur when the mask does not specify an overt response directly but provides only partial information of the response to be given? Experiment 2 was designed to study priming when the mask serves as a cue that indicates the responding hand without specifying the particular overt response. Following the logic of Experiment 1, perceptual and behavioral effects of the prime were assessed by separate tasks. The prime recognition task was used for testing how well the participants could perceive the prime stimulus. An analogous choice RT task was used to determine whether primes can affect partial precuing of motor actions. It was expected that the perceptual and behavioral effects of primes would be dissociated by opposite time courses.

\section{EXPERIMENT 2 Priming of Motor Precuing}

Experiment 2 was designed to determine whether priming effects can be obtained when the mask is not the imperative response signal that fully specifies the response but, rather, a precue indicating part of the motor response. It is well known that choice RT is reduced when advance information about the response is provided before the imperative response signal (Requin, Brener, \& Ring, 1991). For example, Miller (1982) had participants respond to the size and the name of letters with a choice response. In one condition, the letter name specified the response hand (left or right), and the letter size indicated the response finger (middle or index finger). In another condition, letter size specified the hand, and letter name indicated the response finger. Precuing effects were found when the easily discriminable letter name specified the hand (Miller, 1982). It was reasoned that these effects resulted because the information in the precue could be used to specify the parameters of a motor program in advance of the imperative response signal (Rosenbaum, 1980). Advance parameter specification can speed up RT because parameter specification is time consuming (Keele, 1981). Experiment 2 investigated whether even masked primes can lead to hand precuing effects.

It is important to note that response priming effects such as those in Experiment 1 had to be distinguished from the priming effects of precuing paradigms used in this and the following experiments. To this end, that the participants should simply combine the precue with the target stimulus and respond to the resulting complex stimulus event had to be avoided. Otherwise, the priming effects in cuing paradigms might result simply from a complex stimulusresponse mapping in which the participants associated certain combinations of cues and target stimuli to specific motor responses. Therefore, the participants were instructed in all the precuing experiments to process the cue prior to the target stimulus. In addition, they were asked, after each choice RT session, how they had processed cues.

\section{Method}

Participants. Six new students from the University of Braunschweig (4 women, 2 men), from 23 to 40 years of age $(M=$ 27.3 years), participated in the experiment. Five reported that they were right-handed. Each participant took part in four 1-h sessions, receiving course credit for participation.

Stimuli. Prime and mask stimuli were identical to those in Experiment 1 (see Figure 1). Two identical color bars (green or red) were presented as targets $102 \mathrm{msec}$ after the mask for $102 \mathrm{msec}$ at about $1.8^{\circ}$ of visual angle above and below fixation. Color bars were about $2.1^{\circ}$ and $0.3^{\circ}$ in width and height, respectively.

Tasks. (1) The participants had to respond to red bars with their middle fingers and to green bars with their index fingers. A shape cue informed them which hand to use: A square indicated a righthand response, and a diamond indicated a left-hand response. (2) In addition, they did the prime recognition task as in Experiment 1.

Procedure and Design. Experiment 2 differed from Experiment 1 in that the mask served as a precue that specified the response hand, whereas the response finger was specif ied by the color of the target bars. In contrast to Experiment 1, the shape of the mask did not fully specify the response but did specify the correct response hand (see Figure 2). A practice session was followed by two sessions with the choice RT task, together making up 96 replications for each of the 12 experimental conditions resulting from the combination of six levels of SOA and two levels of prime-mask congruency, and by a final session with the prime recognition task, consisting of 48 replications of each condition. The participants were instructed to process the cue prior to the target stimulus.

\section{Results}

After each choice RT session, the participants were given questions concerning their behavior during the session. All the participants reported having used cues to prepare the indicated response hand. The participants were asked to rate "How well could you prepare the indicated hand prior to the target stimulus?" on a 5-point scale ranging from very badly to very well. In 11 out of the total of 12 choice RT sessions, the participants could prepare the hand well or very well prior to the target stimulus. These subjective reports suggest that the participants processed the cue prior to the target, instead of using a complex stimulus-response mapping strategy.

Errors. Errors occurred on $4.4 \%$ of the trials. Mean error rates increased with increases in SOA by $3.1 \%$, $3.1 \%, 3.9 \%, 3.6 \%, 4.7 \%$, and $7.6 \%$ for each SOA, respectively $\left[F(5,25)=3.27, M S_{\mathrm{e}}=0.014, p<.05\right]$. The effect of congruency on error rates was modulated by SOA: On congruent trials, error rate was below $5 \%$ at any SOA. On incongruent trials, however, error rate increased with increases in SOA to above 12\% (see Table 2 

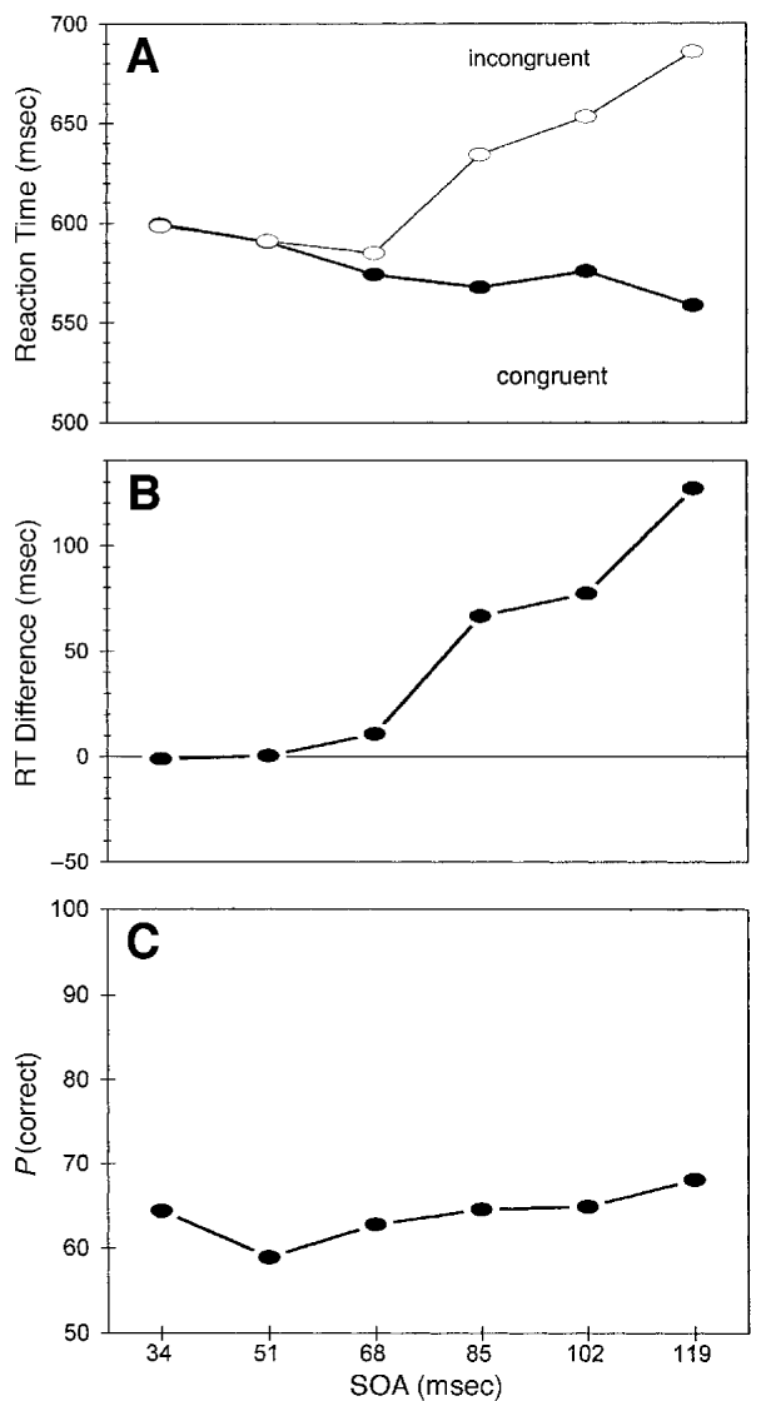

Figure 4. Priming of precued responses and prime recognition as a function of stimulus onset asynchrony (SOA) in Experiment 2. (A) Effects of congruent and incongruent primes on mean choice reaction time (RT). (B) Priming function calculated as the difference between RTs on incongruent and congruent trials. (C) Time course of prime recognition: probability of correct prime recognition.

for means). This was confirmed by the significant interaction of SOA and congruency $\left[F(5,25)=8.86, M S_{\mathrm{e}}=\right.$ $0.014, p<.01]$.

RT. Primes influenced motor precuing effects, as was shown by the effect of congruency, with means of 578 and $625 \mathrm{msec}$ for congruent and incongruent trials, respectively $\left[F(1,5)=28.5, M S_{\mathrm{e}}=1,391, p<.01\right]$. Mean RTs in Figure 4A show that priming depended on SOA: RT for congruent trials decreased with increases in SOA, whereas RT for incongruent trials increased $[F(1,5)=$ $15.8, M S_{\mathrm{e}}=81, p<.05$, and $F(1,5)=17.5, M S_{\mathrm{e}}=752$, $p<.01$, respectively]. The interaction of SOA and congruency was significant $\left[F(5,25)=21.8, M S_{\mathrm{e}}=371\right.$, $p<.001]$. Figure 4B gives the priming function showing that priming began at the $68-\mathrm{msec}$ SOA and reached a magnitude comparable to that in Experiment 1 with long SOAs.

Prime recognition. Overall, prime recognition responses were correct in $63.9 \%$ of the trials. Proportion correct for each SOA is given in Figure 4C. Prime recognition did not show significant effects of SOA, $[F(5,25)=$ $1.1, p=.36]$, which was most likely due to large individual differences in the time course of masking. Another way of checking whether the priming effect depends on how well participants recognize the prime consists in contrasting these participants with the best overall performance $(70.8 \%)$ and with the worst (57.0\%). Figure 5A gives the time course of prime recognition for the three best and the three worst prime recognizers, showing that prime recognition performance increased with increases in SOA for the participants with good performance but decreased for poor prime recognizers. Nevertheless, the priming functions of the two groups given in Figure 5B show almost identical time courses. Thus, across participants, the time course of priming did not depend on prime recognition.

\section{Discussion}

Experiment 2 showed priming in a precuing paradigm and demonstrated the dissociation between priming and prime recognition. RTs showed priming effects that increased with SOA, whereas prime recognition performance was not significantly affected by SOA. An analysis of individual subjects' data showed that the priming function was almost the same irrespective of how well the participants recognized the primes. This pattern of results echoes Experiment 1, in which priming did not depend on prime recognition.

Did these priming effects result from priming in a complex stimulus-response assignment? For instance, the participants could have mapped the complex stimulus combination square-plus-green-bars to a right-hand response with the index finger and the complex stimulus diamond-plus-green-bars to a left-hand response with the index finger. To avoid any strategy like this, the participants were systematically motivated to process the visual cue prior to the following target stimulus in this and all following experiments. Post hoc reports in interviews after choice RT sessions revealed that the participants had followed instructions and had effectively used a sequential strategy in which the cue was processed prior to the target. Therefore, it can be concluded that the present priming effects did not result from complex stimulus-response assignments.

Although prime and mask stimuli were physically identical in the first four experiments of this study, the time course of prime recognition was very different for some participants. However, interindividual differences are not unusual in psychophysical research (see Breitmeyer, 1984; Jensen, 1996). Although the reason for interindividual differences in the present experiment is not 

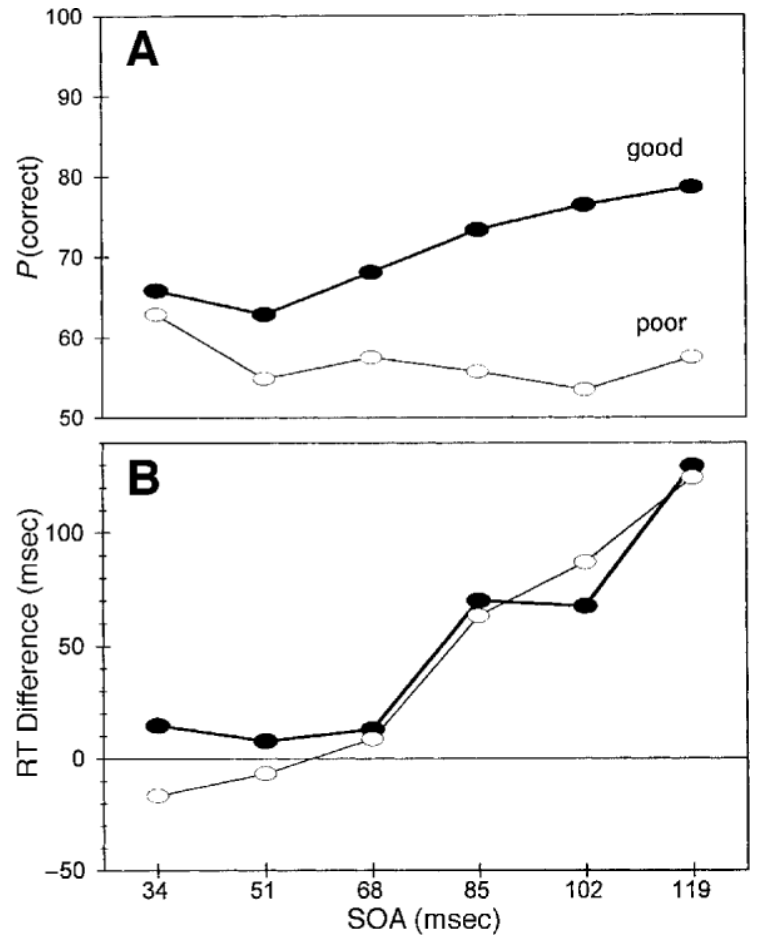

Figure 5. Priming and prime recognition as a function of stimulus onset asynchrony (SOA) in Experiment 2, separated for participants with good and poor prime recognition. (A) Time course of prime recognition: probability of correct prime recognition. (B) Priming functions calculated as the difference between reaction times (RTs) on incongruent and congruent trials for good and poor prime recognizers.

entirely clear, at least two possibilities come to mind. On the one hand, metacontrast masking might have been based on low-level visual mechanisms (Breitmeyer, 1984). Thus, interindividual differences could have been due to physiological differences between participants' visual systems. On the other hand, Ramachandran and Cobb (1995) have demonstrated attentional modulations of metacontrast masking. These attentional effects suggest that different time courses in prime recognition could also arise from different strategies in the discrimination task. For the present study, however, it is most important that almost identical time courses of priming effects were found despite large individual differences in the time course of prime recognition performance, because this dissociation suggests that priming effects and prime recognition arise from different processes.

Priming of motor precuing goes beyond previous findings of direct response priming, which have been explained by postulating a visuomotor route leading to the activation of motor responses (e.g., Leuthold \& Kopp, 1998; Neumann \& Klotz, 1994; Vorberg et al., in press). According to Rosenbaum (1980), partial advance information conveyed by a precue is used to specify action parameters before the imperative response signal provides the parameters that fully specify the motor program.
Priming of precuing indicates that the prime can also be used for specifying action parameters. Because priming of precuing follows a different time course than does prime recognition, this finding is consistent with the view that certain visuomotor processes operate independently of how well participants can consciously perceive the effective stimulus (Leuthold \& Kopp, 1998; Neumann \& Klotz, 1994; Vorberg et al., in press). However, the findings from Experiment 2 are at odds with the hypothesis that direct parameter specification requires that "all parameters of the to-be-executed action have already been specified ... except for those that are specified by the stimulus itself" (Neumann \& Klotz, 1994, p. 144). Instead, the results indicate that some visuomotor processes can operate independently from conscious perceptual recognition even when the action is only partially specified and important parameters have to be provided by the forthcoming imperative response signal.

Direct priming of motor responses (Experiment 1), as well as priming of motor precuing (Experiment 2) dissociated from prime recognition, fits with Milner and Goodale's (1995) notion of a dorsal pathway that transmits visual information to the motor system. Similar to the electrophysiological evidence showing motor activation in direct motor priming (Dehaene et al., 1998; Eimer \& Schlaghecken, 1998; Leuthold \& Kopp, 1998), electrophysiological evidence from precuing studies indicates that advance information about the responding hand can lead to activation of the motor cortex (e.g., Leuthold, Sommer, \& Ulrich, 1996). Therefore, it is tempting to assume that mechanisms leading to priming of motor precuing might be located in the same structures as those leading to direct response priming. However, the question arises, can other mental operations also be influenced by external stimuli, without conscious perception? The following experiments were designed to study whether masked primes can also affect nonmotor operations, such as attention and cognitive control operations.

\section{EXPERIMENT 3 Priming of Attention}

Experiment 2 demonstrated priming effects in a precuing paradigm in which the precue conveyed advance information about the likely response. In Experiment 3, the precue provided information about the likely stimulus. Precuing of stimulus information is a common technique for directing a participant's attention to events of interest in the environment (see, e.g., Pashler, 1998). Many everyday situations require that attention be coordinated across sensory modalities. An attempt has been made in several studies in which the precuing technique was used to provide empirical support for the claim that participants can attend to a sensory modality (for a critical review, see Spence \& Driver, 1997). In their recent study, Spence and Driver confirmed previous reports that RT is longer in trials with targets presented in an unexpected modality than in trials with targets presented in the 
expected stimulus modality. This indicates that people can indeed selectively attend to the auditory or the visual modality. Can stimuli outside awareness also direct attention to the auditory or the visual modality? To answer this question, in Experiment 3, precuing was employed to direct attention to the auditory or the visual modality.

\section{Method}

Participants. Six new students from the University of Braunschweig (3 women, 3 men), from 20 to 27 years of age $(M=$ 22.8 years), participated in the experiment. Five reported that they were right-handed, and all had normal or corrected-to-normal vision. Each participant took part in five 1-h sessions, receiving course credit for participation.

Tasks. (1) The participants responded to the high (low) pitch tone and to the red (green) color bars by pressing the left (right) ALT key on the keyboard with the left (right) index finger. To know which stimulus modality to attend to, they had to use a shape cue: Diamond-shaped mask stimuli indicated that the participant should respond to the tone; squares indicated that the participant should respond to the color. (2) In addition, the participants did the prime recognition task, as in Experiment 1.

Stimuli and Procedure. The prime and mask stimuli were identical to those in Experiment 1 (see Figure 1). On half of the trials, a visual target was presented after the mask: Two identical color bars (green or red) were shown above and below fixation. On the other half of the trials, the target was a high or a low pitch tone (1500 vs. $300 \mathrm{~Hz}$ ), which was presented by a loudspeaker located $12^{\circ}$ of visual angle below the fixation point. To motivate the participants to use the cue, the stimulus display was equivocal in two thirds of the trials in which one of the visual stimuli was accompanied by one of the auditory stimuli. In half of these trials, visual and auditory stimuli were associated to the same response, and they were associated to alternative responses in the other half. Thus, in at least one third of trials with incompatible stimuli, the participants had to use the cue to know what to do. Note that in Experiment 1, the same color bars and tones had been presented as irrelevant distractors. The procedure was identical to that of Experiment 2, except that the participants were instructed to use cues to shift their attention to the indicated stimulus modality. The sequence of stimulus events is given in Figure 2.

Design. In this experiment, the mask served as a precue that indicated which stimulus modality to attend to. In contrast to Experiment 2, the cue did not allow preparation of any motor part of the action, but the participants could shift attention to the indicated stimulus modality. The experiment followed the same logic as that in the previous experiments, with SOA and congruency as independent variables. The independent variable of distractor presence varied: Two thirds of the trials were with and one third of the trials were without a distractor in the irrelevant modality.

\section{Results}

After the choice RT sessions, all the participants reported having used cues to concentrate on the indicated stimulus modality or to ignore the alternative stimulus modality. None of them had used cues to prepare stimulusresponse mappings. In 14 out of 18 sessions, the participants reported that they could prepare well or very well for the indicated stimulus modality prior to the target stimulus. These subjective reports suggest that the participants processed the cue prior to the target by shifting their attention to the indicated stimulus modality.

Errors. Errors occurred on 3.4\% of the trials. Distractor presence had a significant effect: The error rate was increased (3.9\%) in trials with a distractor, as compared with trials without $\left[2.3 \% ; F(1,5)=27.3, M S_{\mathrm{e}}=\right.$ $0.02, p<.01]$. Although the interaction of SOA and congruency failed to reach significance $(p=.11)$, the error data in Table 2 suggest that incongruent primes produced more errors when the SOA was long. To increase the power of the analysis, error rates were averaged for the first and the last three levels of SOA. The a posteriori analysis of congruency and SOA (short vs. long) revealed a significant interaction $[F(1,5)=13.4, p<.05]$.

RT. The effect of primes on attention to the relevant stimulus modality was reflected in the effect of congruency, with means of 467 and $489 \mathrm{msec}$ for congruent and incongruent trials, respectively $\left[F(1,5)=25.9, M S_{\mathrm{e}}=\right.$
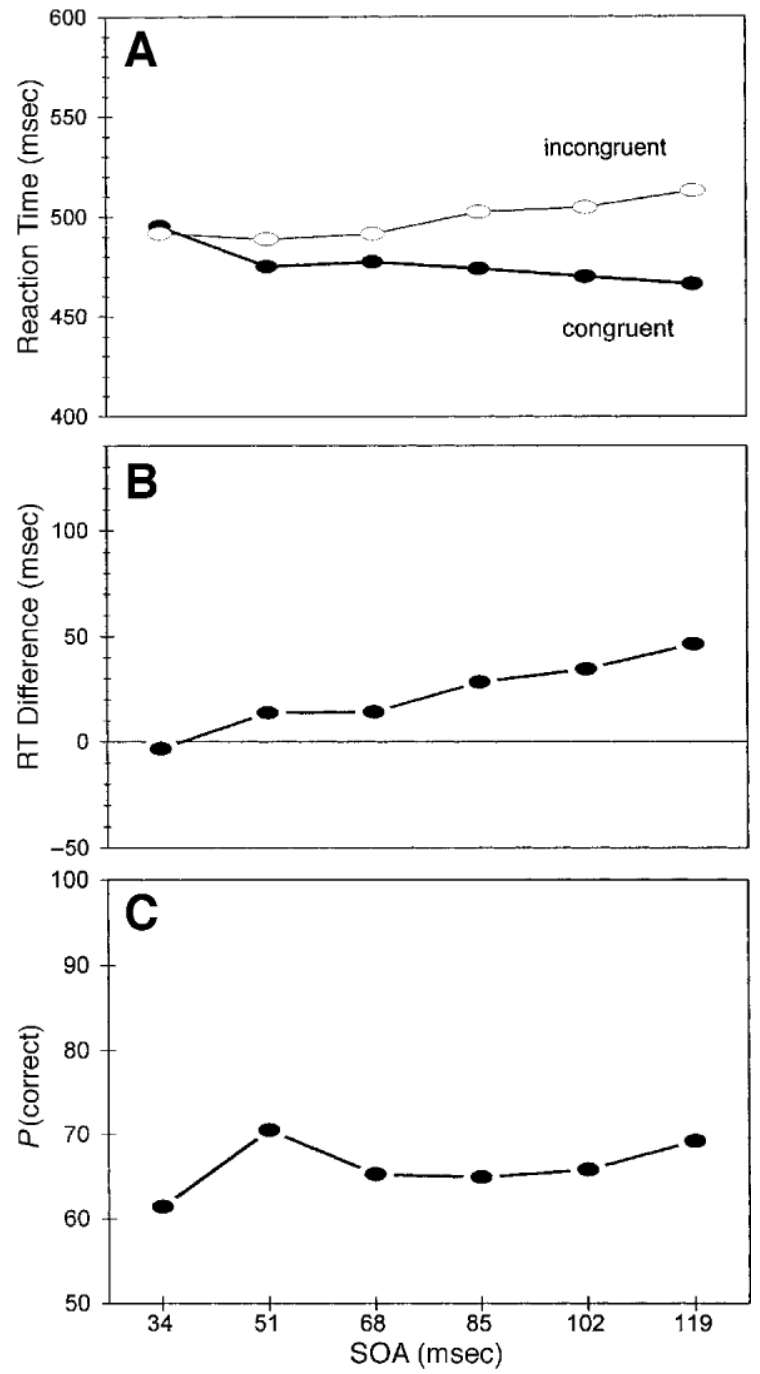

Figure 6. Priming of attention and prime recognition performance as a function of stimulus onset asynchrony (SOA) in Experiment 3. (A) Effects of congruent and incongruent primes on mean choice reaction time (RT). (B) Priming function calculated as the difference between RT on incongruent and congruent trials. (C) Time course of prime recognition performance: probability of correct prime recognition. 
697, $p<.01$ ]. This priming effect depended on SOA, as is shown in Figure 6A. On congruent trials, mean RT decreased with increases in SOA, but it increased with increases in SOA on incongruent primes $[F(1,5)=22$, $M S_{\mathrm{e}}=21, p<.01$, and $F(1,5)=11.2, M S_{\mathrm{e}}=67, p<$ .05 , respectively]. Again, the priming function given in Figure 6B shows an almost linearly increasing effect of attentional priming, but the slope was below one. Priming of attention depended neither on the presence of a distractor nor on target stimulus modality. These conclusions were backed up by a statistical analysis: The interaction of SOA and congruency was significant $\left[F(5,25)=22.1, M S_{\mathrm{e}}=80, p<.001\right]$. Although the presence of a distractor prolonged mean RT from 459 to $497 \mathrm{msec}\left[F(1,5)=10.7, M S_{\mathrm{e}}=4,890, p<.05\right]$, neither the effect of congruency $[F(1,5)=2.9, p=.15]$ nor the SOA $\times$ congruency interaction was significantly modulated by distractor presence $[F(5,25)=0.9, p=.46]$. In other words, the priming effect increased with increases in SOA in trials with and without distractors. ${ }^{2}$

Prime recognition. Overall, prime recognition responses were correct in $66.2 \%$ of the trials. Proportion correct for each SOA is given in Figure 6C. The effect of SOA was not significant, because of individual variability in prime recognition performance $[F(5,25)=0.6$, $p=.57]$. Figure 7A gives the time course of prime recognition performance for the three best $(76.5 \%)$ and the three worst $(55.9 \%)$ recognizers, showing that prime recognition increased with increases in SOA in those participants with good overall performance but decreased in the worst recognizers. Figure 7B depicts the priming functions of the two groups, which were almost identical. Priming effects were larger in the participants with poor prime recognition. With $\mathrm{SOA}=85$ and $102 \mathrm{msec}$, prime recognition was actually at chance levels, with $50.5 \%$ and $51.5 \%$ correct $[t \mathrm{~s}(2)=0.1$ and $0.6, p>$ $.60]$ in the group with poor prime recognition. Nonetheless, the priming effect approached 36 and $43 \mathrm{msec}$, respectively, in these conditions (Figure 7B). At the same levels of SOA, prime recognition was well above chance levels in the group with good prime recognition, with $79.4 \%$ and $80.2 \%$ correct, but their priming effects measured 21 and $26 \mathrm{msec}$, respectively. Thus, across participants, the priming effect was not positively correlated with prime recognition performance.

\section{Discussion}

Experiment 3 showed that attention could also be primed and that priming was dissociated from prime recognition performance. RTs to the relevant target stimuli showed substantial priming effects on attention, which increased with increases in SOA. This priming effect on RT was confirmed by the error data, which increased with increases in SOA on incongruent trials. Note that the presence of distractor stimuli in the irrelevant modality affected neither the priming effect nor its time course. An analysis of individual participants showed that the time course of priming was almost the
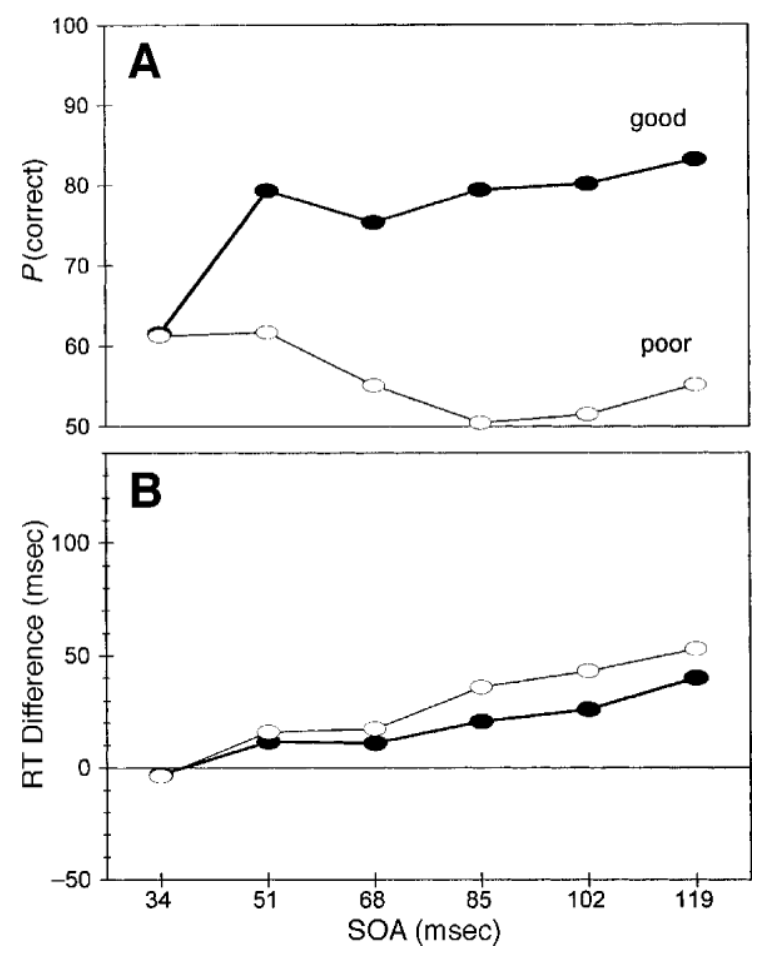

Figure 7. Priming and prime recognition performance as a function of stimulus onset asynchrony (SOA) in Experiment 3, separated for participants with good and poor prime recognition performance. (A) Prime recognition performance: probability of correct prime recognition. (B) Priming functions calculated as the difference between reaction times (RTs) on incongruent and congruent trials for good and poor prime recognizers.

same in the best and the worst prime recognizers, although prime recognition performance increased with increasing SOA in the former group (Type A masking functions; Breitmeyer, 1984) but decreased in the latter (Type B masking functions). This dissociation across participants indicates that priming effects on attention arise from mechanisms that are distinct from those of prime recognition. This pattern of results replicates those of Experiment 1 and Experiment 2, in which priming of motor responses and priming of precuing were dissociated from prime recognition. Furthermore, at SOAs of 85 and $102 \mathrm{msec}$, priming effects were larger in the group of participants that could not discriminate primes above chance levels than in the group of participants that discriminated primes well above chance levels. If we assume that chance performance in prime recognition indicates absence of awareness, this finding is evidence for priming without awareness, for two reasons. First, substantial priming effects occurred when the participants were not aware of the primes. Second, priming effects were about the same regardless of whether the participants were aware of the primes or not.

In line with Experiment 2, the present experiment underscores that priming effects can occur in precuing par- 
adigms. However, in contrast to Experiment 2, the precue in Experiment 3 did not convey direct information about the overt motor response. Therefore, priming of attention cannot be accounted for by processing along a visuomotor pathway leading immediately to action, as has been proposed to explain response priming effects. (Leuthold \& Kopp, 1998; Neumann \& Klotz, 1994; Vorberg et al., in press). Instead, these results suggest that information conveyed by primes can be analyzed independently of prime recognition and can be used by the system to guide attention to different stimulus modalities. This finding clearly goes beyond previous findings of motor effects of masked stimuli and indicates that, in a given task context, visual processing can extract enough information from masked stimuli to progress with mental operations on the basis of this stimulus information, without producing conscious representations of the effective stimulus.

Apparently, priming of motor responses and priming of attention is (1) dissociated from prime recognition performance and (2) increases with increases in SOA. These similarities between attentional and motor priming suggest that both priming effects arise from the same mechanism. However, motor priming increased with increases in SOA with a slope approaching one, whereas attentional priming increased with a substantially smaller slope (cf. Figures 3, and 4 with Figure 6). On the one hand, this difference suggests two different mechanisms in motor priming and attentional priming. Alternatively, and more parsimoniously, in attentional priming, the priming effect could increase with increases in SOA more slowly because primes affect perceptual representations with a lower rate, as compared with the effect of primes on motor representations (see the General Discussion section).

\section{EXPERIMENT 4 Priming of Cognitive Control Operations}

Experiment 4 tested the extent of nonmotor priming effects. Instead of attention's being primed, Experiment 4 studied whether other cognitive control operations could also be influenced by masked primes. Research on cognitive control assumes that we can adopt a particular configuration of our cognitive system to perform a given task, such as making coffee or comprehending a spoken sentence (Allport, Styles, \& Hsieh, 1994; Rogers \& Monsell, 1995). According to this, we can prepare to perform a task, which involves linking and configuring processing modules that are responsible for different aspects of the task, such as stimulus processing, response selection, or response execution (e.g., Monsell, 1996). This ability to reconfigure our cognitive system allows us to respond in different ways to one particular stimulus on the basis of our intentions. It is assumed that cognitive configurations for well-learned tasks are represented in memory by abstract task-sets. To perform a task, the appropriate task-set has to be selected, activated, and maintained by some endogenous control system. In Experiment 4, an attempt was made to study whether stimuli that remain unaware can affect cognitive control operations involved in task-set selection and activation. The experiment used precues that specified the task to be performed on multidimensional auditory stimuli. In contrast to Experiment 3 , the stimulus modality remained constant in Experiment 4 , and the participants responded to identical stimuli according to different stimulus-response mappings in different trials. Therefore, instead of specifying any response parameter or the stimulus modality, the precue in Experiment 4 specified the cognitive operation necessary for performing the task.

Note that this distinction between Experiment 3 and Experiment 4 follows the traditional view, because each of them is typical for research on attention and cognitive control, respectively. However, experiments can be compared alternatively. According to one view, both experiments are simply variants of one or the other issue. Both experiments could be considered variants of selective attention studies: In Experiment 3, selection of stimulus modality was examined, whereas in Experiment 4, selection of a stimulus feature within the auditory modality was studied. Thus, in both experiments, priming effects on selective attention were examined. Alternatively, both experiments could be considered to be studies of cognitive control operations: Experiment 3 involved two different task-sets-namely, one stimulus-response mapping for visual stimuli and another for auditory stimuli-whereas Experiment 4 involved one task-set for pitch discrimination and another for timbre. According to this view, in both experiments, primes and cues affected cognitive control operations related to the selection of task-sets. These different views regarding the relation between these experiments are possible because of the difficulty of defining with precision what constitutes a "task" (Rogers \& Monsell, 1995). Although this issue is not entirely settled, I prefer the distinction typically found in the literature. According to this traditional distinction, in Experiment 3 and Experiment 4, different issues were studied, because cuing of stimulus modality is used in studies of attention (e.g., Spence \& Driver, 1997), whereas cuing of the task to be performed with a multidimensional stimulus is used in studies of cognitive control operations (Allport et al., 1994; Rogers \& Monsell, 1995).

\section{Method}

Participants. Six new students from the University of Braunschweig ( 4 women, 2 men), from 20 to 34 years of age $(M=$ 24 years), participated in the experiment. All reported that they were right-handed and had normal or corrected-to-normal vision. Each participant took part in four 1 -h sessions, receiving course credit for participation.

Stimuli. Prime and mask stimuli were identical to those in all the other experiments (see Figure 1). After the mask, a MIDI sound was presented over headphones. The sound was either that of a piano or that of a marimba with high or low pitch, which differed by seven tones. No visual stimulus accompanied the presentation of the sounds. Except for the target stimulus, the sequence of stimuli and the procedure were identical to those in Experiment 2 (see Figure 2).

Tasks. (1) The participants indicated either the pitch (low vs. high), or the timbre (piano vs. marimba) of the sound by pressing 
the left or the right ALT key on the keyboard with their left or right index fingers. The task in effect was indicated by the shape cue: Diamond-shaped mask stimuli indicated the pitch task; squares indicated the timbre task. (2) In addition, they did the prime recognition task as in Experiment 1.

Design and Procedure. Experiment 4 differed from previous experiments only because the mask served as a precue that indicated the task to be performed on the multidimensional stimulus and the cue could not be used for preparation of stimulus modality or any motor preparation.

\section{Results}

In interviews after the choice RT sessions, the participants reported having used cues to concentrate on the indicated stimulus aspect. All of them processed the cues prior to the target. They reported that, in 7 out of 12 sessions, they could prepare well for the indicated stimulus aspect prior to the target stimulus.

Errors. Errors occurred on $4.8 \%$ of the trials. Error rates were not significantly affected by any experimental variable (see Table 2 for means).

RT. The priming effect on cognitive control operations was reflected in the effect of congruency, with means of 608 and $635 \mathrm{msec}$ for congruent and incongruent trials, respectively $\left[F(1,5)=36.8, M S_{\mathrm{e}}=363\right.$, $p<.01]$. This priming effect was modulated by SOA as is shown in Figure 8A. On congruent trials, mean RT decreased with SOA, whereas RT increased with SOA on incongruent trials $\left[F(1,5)=5.5, M S_{\mathrm{e}}=189, p=.07\right.$, and $F(1,5)=7.1, M S_{\mathrm{e}}=752, p<.05$, respectively]. The interaction of SOA and congruency was significant $\left[F(5,25)=4.2, M S_{\mathrm{e}}=426, p<.05\right]$. The priming function in Figure 8B shows that priming of cognitive control operations increased almost linearly with SOA.

Prime recognition. Overall, prime recognition responses were correct in $68.4 \%$ of the trials. Figure $8 \mathrm{C}$ shows how prime recognition performance was modulated by SOA: The participants recognized primes better at short SOAs than at longer SOAs. The effect of SOA on arc-sine transformed proportion correct reached significance $[F(5,25)=13.5, p<.01]$. Comparing this masking function in Figure 8C with the priming function in Figure $8 \mathrm{~B}$ shows a double dissociation of priming and prime recognition performance: Whereas the priming effect increased with increases in SOA, prime recognition performance decreased across the same levels of SOA.

\section{Discussion}

Experiment 4 demonstrated priming of cognitive control operations and showed a double dissociation between priming and masking: RTs reflected priming effects that increase with increases in SOA, whereas prime recognition performance changed nonmonotonically. This pattern of results is in line with the previous experiments in this study showing that priming dissociated from prime recognition. In line with Experiment 2 and Experiment 3, the present results adds further evidence for priming effects in precuing paradigms.

In contrast to previous experiments, in Experiment 4, the precue provided advance information that was re-
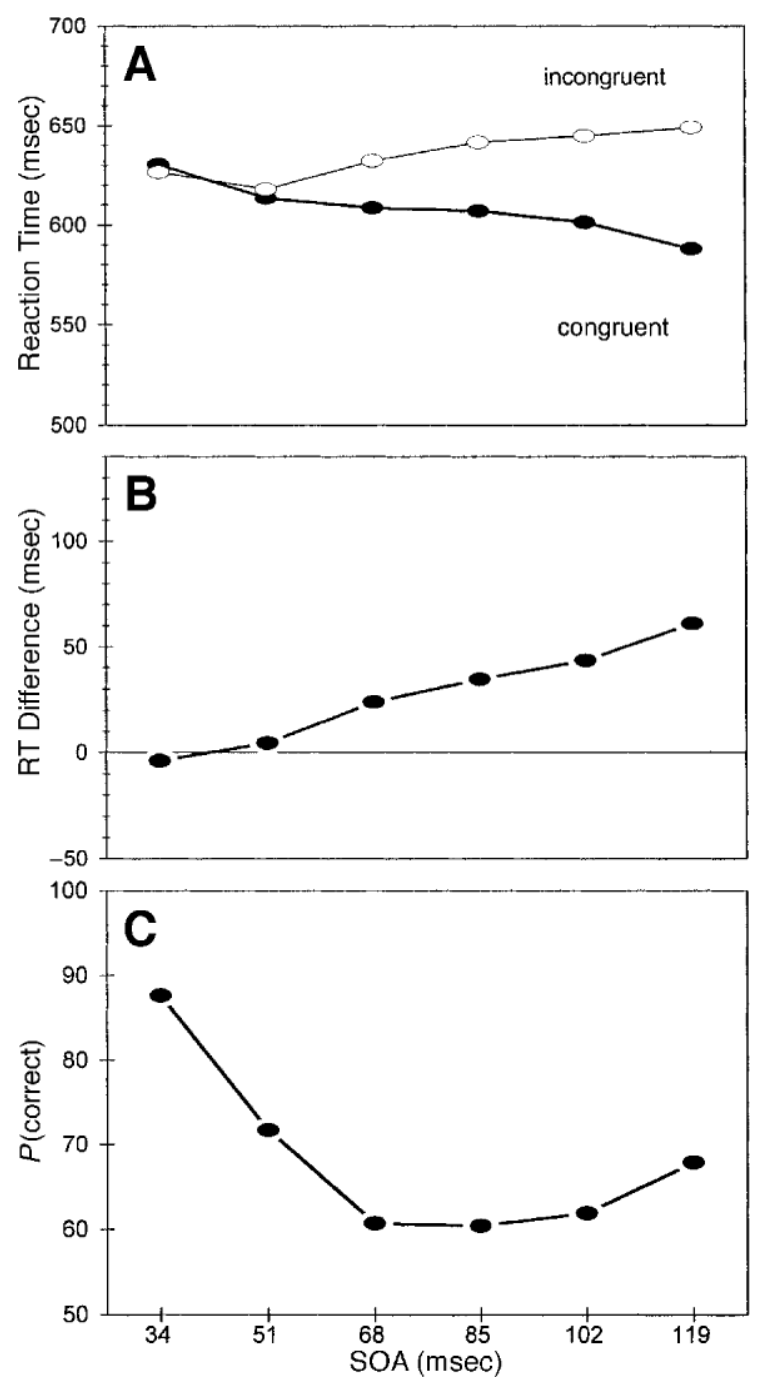

Figure 8. Priming of cognitive control operations and prime recognition performance as a function of stimulus onset asynchrony (SOA) in Experiment 4. (A) Effects of congruent and incongruent primes on mean choice reaction time (RT). (B) Priming function calculated as the difference between RTs on incongruent and congruent trials. (C) Time course of prime recognition performance: probability of correct prime recognition.

quired for selection of task-sets. Note that the participants in Experiment 4 were in a varied mapping condition because they could not respond solely to the sound but had to use the cue signaling which task to perform (Shiffrin \& Schneider, 1977). Given that varied mapping does not become automatic with practice (Rogers \& Monsell, 1995), performance in this task always required deliberate cognitive control. According to this conceptual framework, the present priming effects indicate that primes affected cognitive control operations. Extending previous findings, priming of cognitive control indicates that visual processing can produce an output that can affect cognitive control operations, even though visual processing does not generate mental representations of 
the external stimulus that are sufficient for errorless perceptual reports.

\section{EXPERIMENT 5 Nonmotor Priming With Total Masking}

The previous experiments employed a doubledissociation paradigm to show that priming effects are based on processes other then those responsible for conscious perception of primes. Therefore, prime and mask stimuli were constructed to the end that prime recognition performance decreased with increases in SOA, corresponding to Type $\mathrm{B}$ metacontrast masking functions (Breitmeyer, 1984). However, stimulus conditions that yield Type B metacontrast masking functions rarely lead to total masking at any level of SOA (see Francis, 1997). Therefore, evidence for nonmotor priming without awareness was found only in few a participants in Experiment 3. Nonetheless, on the basis of the results of the doubledissociation paradigm, one could predict that priming effects would occur also when masking is total $\left(d^{\prime}=0\right)$. Therefore, stimulus conditions in Experiment 5 were designed to yield total masking of prime stimuli.

Experiment 5 replicated Experiment 4, because precues specified the task to be performed on multidimensional auditory stimuli. In addition, Experiment 5 extended Experiment 4 , because the position of the diamond-shaped stimulus (left vs. right) served as a precue for the cognitive task (pitch vs. timbre). Congruency of stimulus position has been shown in previous studies (e.g., Klotz \& Neumann, 1999; Neumann \& Klotz, 1994) to produce motor priming effects similar to those produced by the congruency of shape (e.g., Vorberg et al., in press). Therefore, Experiment 5 provides a further comparison of motor and nonmotor priming. If nonmotor priming resembles motor priming, stimulus position congruency should produce nonmotor priming effects comparable to those in Experiment 4 with shape congruency.

From a critical point of view, the priming effects of the previous experiments could have resulted if the participants had consciously perceived primes on a few trials. These few trials could have caused the priming effect, whereas priming might have been absent on other trials in which the primes were not perceived consciously. To control whether nonmotor priming effects result from only a few peculiar trials, Experiment 5 was designed to allow for an analysis of the RT distribution. To this end, Experiment 5 did not use the double-dissociation paradigm, but SOA was fixed at a constant level, and the number of congruent and incongruent trials was increased.

The design of Experiment 4 had been based on the assumption that cognitive control is affected whenever different responses have to be given to the same multidimensional stimuli, because these varied mapping conditions require continuing cognitive control (e.g., Allport et al., 1994; Rogers \& Monsell, 1995; Shiffrin \& Schneider, 1977). Therefore, the instructions in Experiment 4 did not further emphasize task-set selection but simply asked the participants to attend to that aspect of the stimuli indicated by the cue. In contrast, in Experiment 5, an attempt was made to further emphasize task-set selection, instead of simply manipulating attention. Therefore, the participants were systematically instructed to use cues to select the indicated task prior to the target.

\section{Method}

Participants. Eleven new students from the University of Braunschweig (10 women, 1 man), from 19 to 37 years of age $(M=$ 23.3 years), participated in the experiment. Ten of them reported that they were right-handed, and all had normal or corrected-to-normal vision. Each participant took part in three 1-h sessions, receiving course credit for participation.

\section{Congruent}

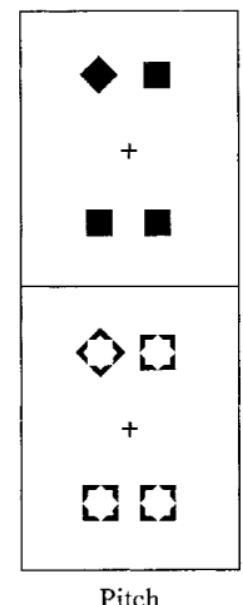

Pitch

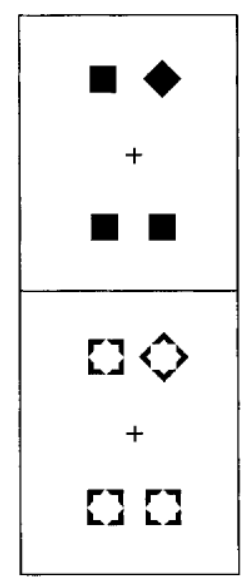

Timbre

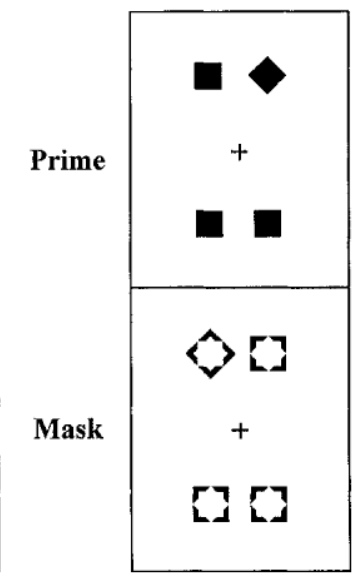

Task

Pitch
Incongruent

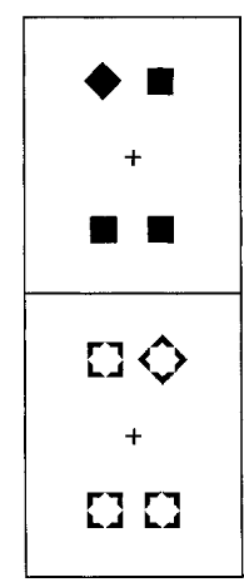

Timbre

Figure 9. Stimuli used for metacontrast masking in Experiment 5. On half the trials, primes were congruent to masks. Note that one prime-mask pair was presented in each trial. 


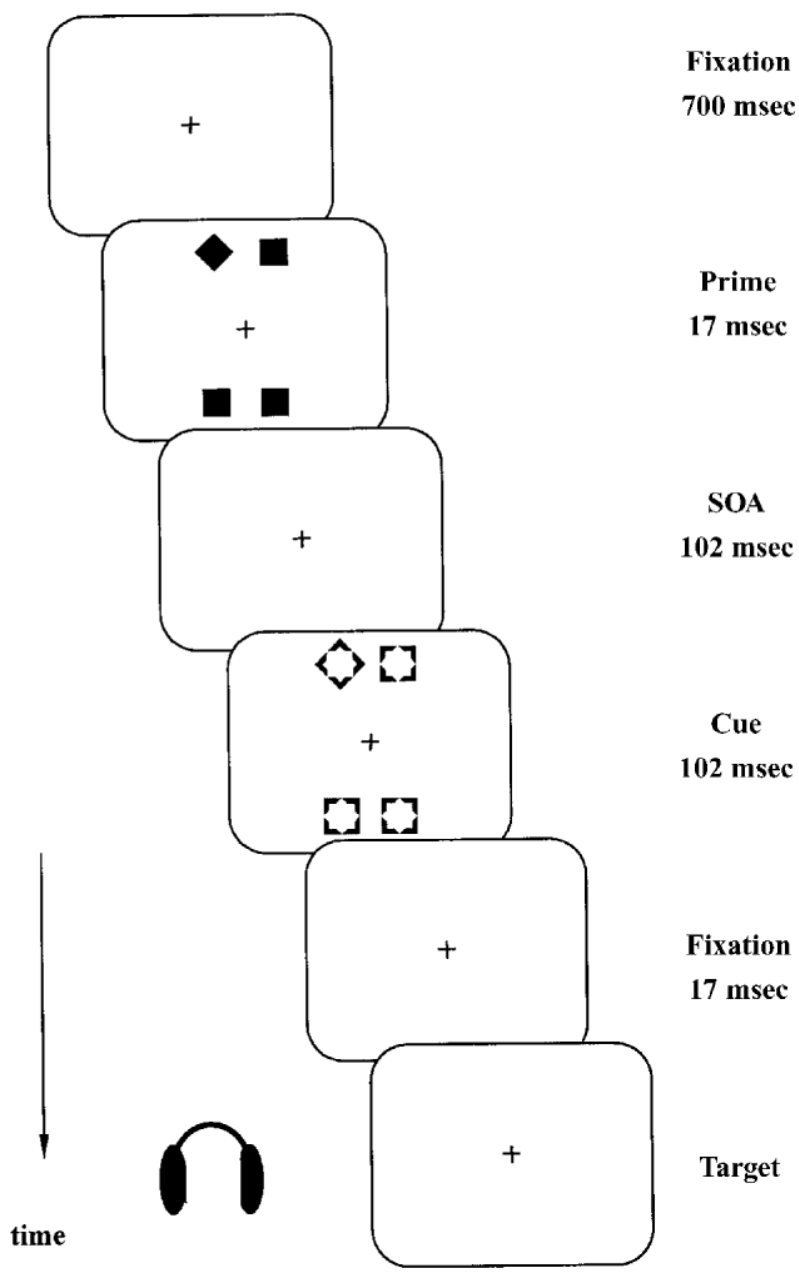

Figure 10. Schematic diagram of stimulus events in Experiment 5 . Sounds presented via headphones served as targets in the choice reaction time (RT) task in which the participants used the position of the diamond in the mask display as a cue to prepare for the task in effect (pitch vs. timbre). Priming effects were assessed by the effects of prime-mask congruency on RT. In the prime recognition task, the participants reported the position of the prime (left vs. right).

Stimuli. The stimuli differed from those in the previous experiments in the following respect (see Figure 9). On each trial, one diamond-shaped cue appeared together with three squares, which served as distractors. Prime and mask displays consisted of the diamonds and squares that were used in the other experiments of this study as primes and masks, respectively. The diamond appeared together with one square about $3^{\circ}$ above or below fixation. Two squares served as a distractor pair presented on the side of fixation opposite to the diamond-square pair. In half of the trials, the diamondsquare pair was a left diamond and a right square; in the other half, the arrangement was reversed. The outer distance between masking stimuli extended about $4.3^{\circ}$. The prime (duration, $17 \mathrm{msec}$ ) was followed by the mask (duration, $102 \mathrm{msec}$ ), with a constant SOA of $102 \mathrm{msec}$. On congruent trials, the diamond in the prime display was placed at the same position as the diamond in the mask display. On incongruent trials, the diamond in the prime display was placed at the same position as the square in the diamond-square pair of the mask display. Diamonds in prime and mask displays were both either above or below fixation on a given trial. Primes were congruent in half of the trials, with congruency varying randomly between trials. One of the MIDI sounds used in Experiment 4 was presented over headphones $17 \mathrm{msec}$ after mask offset. The sequence of events is given in Figure 10.

Tasks. (1) In the choice RT task, the participants indicated either the pitch (low vs. high) or the timbre (piano vs. marimba) of the sound by pressing the left or the right ALT key on the keyboard with their left or right index fingers. The task in effect was indicated by the position of the diamond: Diamond-shaped mask stimuli on the left side indicated the pitch task; diamonds on the right side indicated the timbre task (see Figure 9). (2) In the last session, the participants were informed about the presence of primes and were to respond to the position of prime diamonds, without pressure with respect to speed: They responded to a diamond on the left (right) with a left- (right-) hand response.

Procedure. (1) In the choice RT task, the participants were instructed to proceed sequentially by first attending to the position of the diamond, to determine and prepare for the task in effect, and then responding to the auditory stimulus. The computer monitored for a response within 2,120 msec after mask onset. In case of a wrong response, the word FEHLER (English error) was presented for $1 \mathrm{sec}$, followed by a rest of $2 \mathrm{sec}$. The next trial began after a random interval with a mean of $1,500 \mathrm{msec}$. At the end of the choice RT session, the participants were systematically asked several questions concerning the visual stimulus displays.

(2) At the beginning of the session with the direct prime recognition task, the participants were shown all possible prime displays without mask displays and then, in slow motion, prime displays together with mask displays, with a decreasing prime-mask SOA. The participants put on headphones but were instructed to ignore the sounds. They were instructed to identify the position of the diamond in the prime display as accurately as possible with deliberate time and to choose their response on the basis of what they saw or to follow their intuition. Experimental trials were identical to those of the choice RT session, except that the computer monitored for a response within $3 \mathrm{sec}$ after mask offset. In case of a wrong response, visual error feedback was given as in the choice RT task. At the end of the session, the participants were asked whether they had any post hoc impression that they might have perceived some of the primes.

Design. A practice session was followed by the experimental session with the choice RT task and by the final session with the prime recognition task. Each of every possible combination of stimulus conditions was presented with equal frequency, varying randomly between trials. In both sessions, a practice block was followed by five blocks of 64 trials each. Thus, in each task, the data of 160 replications of each of the two levels of congruency (congruent vs. incongruent) were collected. The priming effect was analyzed by comparing reaction times on congruent and incongruent trials in the choice RT session. Prime recognition performance was analyzed by averaging $d^{\prime}$ determined separately for mask displays with diamonds on the left and for those with diamonds on the right.

\section{Results}

In interviews after the choice RT session, the participants all reported that they could prepare well or moderately for the required task prior to the target stimulus. Thus, these subjective reports suggest that the participants followed instructions and effectively used a sequential strategy in which the cue was used for task selection prior to target processing.

Behavioral effects of primes. Overall, errors on congruent $(5.5 \%)$ and incongruent $(5.6 \%)$ trials did not differ significantly $[F(1,10)<1]$. The priming effect on cognitive control operations was reflected in the effect 


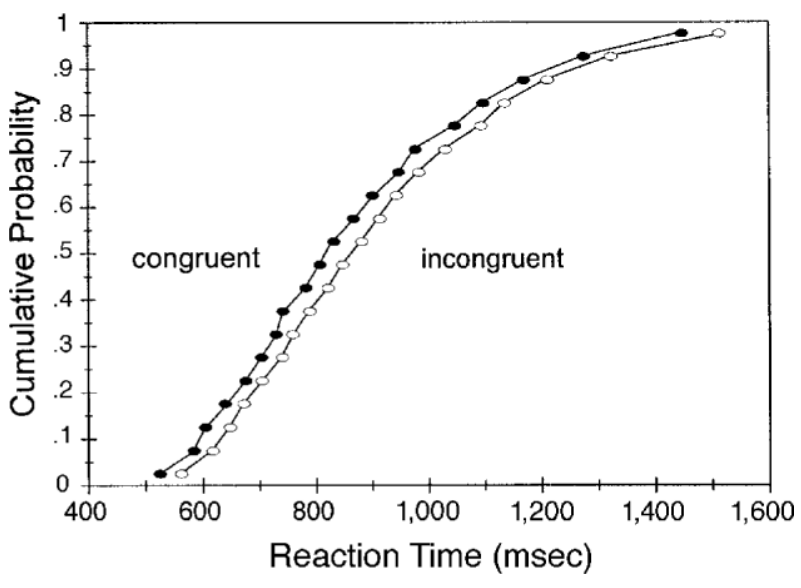

Figure 11. Vincentized cumulative distribution functions of reaction times on congruent and incongruent trials in Experiment 5.

of congruency, with means of 848 and 892 msec for congruent and incongruent trials, respectively $[F(1,10)=$ $\left.18.5, M S_{\mathrm{e}}=586, p<.01\right]$.

To see whether the priming effect results only from a few trials, the distribution of RTs was analyzed. Figure 11 shows cumulative distribution functions of RT for correct trials with congruent and incongruent primes. The vertical axis indicates the proportion of RTs less than or equal to the values on the horizontal axis. Each function was obtained by Vincentizing, which involves averaging the RTs associated with each probability from individual participants (Thomas \& Ross, 1980). Figure 11 shows that the entire distribution of RTs was shifted leftward on congruent trials, as compared with incongruent trials. Thus, the priming effect was quite robust across the entire distribution of RTs.

Perceptual effects of primes. Subjective measures revealed that the primes were largely invisible. Table 3 shows priming effects together with subjective and objective measures of prime visibility for individual participants. After the choice RT session, none of the participants spontaneously reported having perceived the masked primes. When asked (in German), "Did you notice the stimuli presented prior to the cue displays?" only 1 participant gave a positive answer. She reported that the diamond appeared first at a different position on some trials. When asked, "Did you notice any flicker?" 5 of the remaining participants responded positive, whereas 5 did not even see any flicker during the choice RT session. After the prime recognition session, the participants were asked, "In how many of the trials did you see the diamond in the prime display in this session?" Responses varied between $0 \%$ and 50\% (see Table 3 ).

Objective measures of prime recognition revealed correct responses in $54.6 \%$ of the trials and a value of $d^{\prime}$ of 0.28 , which was only marginally different from zero $[t(10)=1.9, p=.09]$. Priming effects did not correlate with $d^{\prime}(r=.07, p=1)$ with reports of primes noticed in the choice RT session $(r=2.02, p=1)$, or with the participants' estimates of having seen primes in the prime recognition session $(r=.04, p=1)$. Furthermore, the correlation between $d^{\prime}$ and the participants' reports of having noticed primes in the choice RT session did not reach significance $(r=.56, p=.76)$. Neither did the correlation of $d^{\prime}$ with participants' post hoc estimates of having seen primes in the prime recognition session reach significance $(r=.27, p=1)$.

Analysis of a subset of the participants. Individual prime recognition performance in 7 participants was at chance levels (below 53\% correct responses, $d^{\prime}$ below $0.19)$. The mean $d^{\prime}$ value of this subgroup was zero $[t(6)=0.0]$. Nonetheless, these participants were significantly affected by primes, as is indicated by the significant priming effect of $49 \mathrm{msec}[t(6)=3.0, p=.02]$. Thus, this subset of participants provides clear evidence for priming without awareness in terms of $d^{\prime}=0$.

Table 3

Behavioral and Perceptual Effects of Primes in Experiment 5

\begin{tabular}{|c|c|c|c|c|c|}
\hline \multirow[b]{2}{*}{$\mathrm{P}$} & \multicolumn{2}{|c|}{$\begin{array}{c}\text { Priming Effect } \\
\text { (Incongruent }- \text { Congruent) }\end{array}$} & \multicolumn{3}{|c|}{ Prime Recognition } \\
\hline & RT (msec) & PE $(\%)$ & Prior Noticed & $d^{\prime}$ & Post Hoc Seen $(\%)$ \\
\hline 11 & 22 & -1.3 & nothing & -.36 & 30 \\
\hline 2 & 8 & 3.7 & flicker & -.09 & 0 \\
\hline 4 & -6 & -1.3 & flicker & -.05 & 20 \\
\hline 6 & 49 & -2.5 & nothing & .06 & 30 \\
\hline 5 & 112 & 0.0 & flicker & .09 & 10 \\
\hline 7 & 74 & 0.0 & flicker & .17 & 30 \\
\hline 9 & 82 & 0.6 & nothing & .18 & - \\
\hline 3 & 45 & -0.6 & nothing & .31 & 0 \\
\hline 10 & 26 & 3.7 & nothing & .44 & 25 \\
\hline 1 & 33 & -1.3 & flicker & .93 & 2 \\
\hline 8 & 43 & 0.6 & diamond & 1.35 & 50 \\
\hline
\end{tabular}

Note-Participants' (P) data ordered according to values of $d^{\prime}$. Prior Noticed lists reports of what the participants noticed during the choice reaction time (RT) session prior to information about the presence of primes. Post Hoc Seen lists retrospective estimates of percentages of trials in which the participants saw any hint of primes. These estimates were given at the end of the prime recognition session. 


\section{Discussion}

Experiment 5 replicated priming of cognitive control operations in a paradigm with prime and mask stimuli different from those in Experiment 4 and added further evidence for priming effects in precuing paradigms. In contrast to the other experiments in this study, priming effects of nonmotor operations were found as a function of congruency between the position of prime and mask stimuli. This resembles previous findings of motor priming from experiments in which comparable stimuli were used (e.g., Klotz \& Neumann, 1999; Neumann \& Klotz, 1994). Thus, Experiment 5 provides additional evidence for the view that priming of nonmotor operations is governed by mechanisms similar to those that govern priming of motor responses, because both can be obtained with similar stimulus conditions-shapes, as well as the position of shapes.

Experiment 5 was designed to yield total masking. However, 4 participants showed above-chance prime recognition performance. ${ }^{3}$ Nonetheless, and in line with the other experiments in this study, priming effects were not correlated with measures of prime recognition. Furthermore, substantial priming effects of $49 \mathrm{msec}$ were found in a subset of 7 participants with zero prime sensitivity. Thus, the results of Experiment 5 confirm the conclusions of the previous experiments in this study, which showed that nonmotor priming is dissociated from prime recognition.

\section{GENERAL DISCUSSION}

The present experiments demonstrated that the effects of masked stimuli are not restricted to motor effects but extend to other mental operations necessary for performing a given task. In the following, I will comment on the priming of mental operations, the issue of priming without awareness, the presumed locus of priming mechanisms, and the limits of priming.

\section{Priming of Mental Operations}

Empirical evidence for comparable motor and nonmotor priming by masked stimuli comes from four sources. (1) Congruent and incongruent primes affected RT in every experiment in this study. (2) Similar motor and nonmotor priming effects were found across different stimulus conditions. (3) The effect of the SOA between prime and mask was the same in motor and nonmotor priming, since priming effects increased monotonically with SOA in every instance. (4) Motor, as well as nonmotor, priming did not correlate with prime recognition performance. This was shown within participants by the double dissociation consisting of opposite time courses of priming and prime recognition performance and by the finding of substantial priming effects in conditions with zero prime sensitivity. In addition, nonmotor priming effects did not correlate with prime recognition across participants. Together, these parallel findings support the hypothesis of this study that priming of motor oper- ations and priming of nonmotor operations are governed by comparable mechanisms.

However, two differences between motor and nonmotor priming have to be considered before a final conclusion can be drawn. (1) Priming effects are larger in motor than in nonmotor priming. This is evident in the RT data, as well as in the error data. In order to understand this difference, I ran Monte Carlo simulations on a mathematical model that had been proposed to explain motor priming effects (Vorberg et al., in press). On the basis of the assumption that priming effects result from general mechanisms of masked stimuli on mental representations, it was found that the size of priming effects can differ in motor and nonmotor priming if the impact of primes on motor representations is stronger than their impact on nonmotor representations. (2) Priming effects on error rates differ between motor and nonmotor priming. Priming effects on error rates were found in motor priming but were absent or reduced in nonmotor priming, although they reached significance in attentional priming. This difference between motor and nonmotor priming is less surprising if one assumes that motor priming results from effects on processing stages that are close to the final motor output, as is indicated by neurophysiological findings of priming effects on the motor cortex (e.g., Dehaene et al., 1998; Leuthold \& Kopp, 1998). In contrast, nonmotor priming effects might result from effects on processes that are followed by further processing stages that prevent the system from producing overt response errors after incongruent primes. Therefore, incongruent primes cause overt response errors more frequently in motor priming than in nonmotor priming. Taken together, the differences between motor and nonmotor priming are consistent with the view that priming effects result from the same mechanism that operates at different levels of processing in motor priming, as compared with nonmotor priming. For more on this view, see below.

Do the priming effects found with the precuing paradigm result from a strategy of complex stimulus-response assignments? Or do primes in the different experiments affect different mental operations? To prevent the participants from applying strategies such as complex stimulusresponse mappings or simply processing the cue after target presentation, they were instructed in every experiment to process the cue prior to the target. Interviews after every choice RT session revealed that all the participants processed the cue prior to the target stimulus. Furthermore, several participants consistently reported that the experimental task became very hard, and RTs rose considerably, when they tried to process both stimuli together. Therefore, there is no evidence for the view that priming effects found in the precuing paradigms resulted from any strategy-like complex stimulus-response assignments. Instead, priming effects resulted because the participants used cues to prepare for processing of the following target stimulus.

What mental operations are affected by primes? Did primes affect the same or different mental operations in 
Experiment 3, as compared with the last two experiments? As was mentioned above, the distinction between priming of attention and priming of cognitive control will remain cloudy until what constitutes a task is clearly defined (Rogers \& Monsell, 1995). Although this conceptual problem becomes particularly obvious in studies like the present one, which contrasts both fields of research, it has to be mentioned that it concerns any study on attention or cognitive control (see Rogers \& Monsell, 1995; Spence \& Driver, 1997). However, in the present study, the experimental procedures used in Experiment 3 are typically used in studies on attention. Furthermore, the participants were instructed to use cues in Experiment 3 to shift their attention to the indicated stimulus modality, instead of preparing certain stimulus-response mappings. Systematic evaluation of the participants reports in Experiment 3 showed consistently that they used cues to shift attention to the indicated stimulus modality. In contrast, the experimental procedures used in Experiment 4 and those used in Experiment 5 are typically used in studies on cognitive control. In addition, the participants in Experiment 5 were motivated to use cues to prepare tasks, instead of attending to specific auditory stimulus features. The reports of the participants in Experiment 5 showed that they, indeed, had used cues to prepare the indicated task. For the present, it does not hinder progress if effects in the different experiments are distinguished in a way that corresponds to the distinction in the literature on attention and cognitive control until future research provides the means for clear definitions. Taken together, the results show comparable priming effects when cues are used to prepare mental operations related to response activation, selective attention, or cognitive tasks.

\section{The Controversy Regarding Priming Without Awareness}

What kind of processing is reflected in the effect of primes on mental operations? Does the time course of priming reflect the time course of processes that operate independently of prime awareness? Is the time course of the generation of conscious awareness reflected in the time course of two-choice prime recognition performance? There is an old debate about the dissociation between conscious and unconscious processing, which followed claims that there were effects of stimuli not consciously perceived by participants. Reports often failed to convince skeptics that participants were truly unaware of the effective stimuli (Eriksen, 1960; Holender, 1986). Whether or not masked stimuli had an effect seemed to depend on how strictly experimenters measured participants' awareness of the effective stimuli (Greenwald, 1992; Merikle, 1992). Stimulus effects without stimulus awareness have been reported when subjective awareness was assessed by asking participants whether they had perceived the stimulus. Although such subjective reports of awareness captures the phenomenological distinction between conscious and unconscious perceptual experience (Cheesman \& Merikle, 1986), they have been criticized because these measures might be contaminated by such factors as response bias, criterion settings, or withholding responses (e.g., Cheesman \& Merikle, 1986; Eriksen, 1960; Holender, 1986). Therefore, some critics have demanded that only objective measures of awareness, such as forced-choice discrimination, should be used to show convincingly that participants were unaware of the effective stimulus (e.g., Holender, 1986).

In this line of research, a number of recent studies have reported response priming effects despite chance performance in two-choice prime recognition performance (e.g., Klotz \& Neumann, 1999; Neumann \& Klotz, 1994; Vorberg et al., in press). Similarly, Experiment 5 of the present study demonstrated nonmotor priming despite zero sensitivity for the effective stimulus. However, Reingold and Merikle $(1988,1990)$ have convincingly argued that zero sensitivity in objective measures are evidence for absence of awareness only when the objective measure exhaustively captures all conscious perceptual information. Otherwise, it is always possible to argue that some part of consciously available information was effective that was not reflected by the index of awareness. Consequently, Merikle and colleagues (e.g., Cheesman \& Merikle, 1986; Merikle \& Joordens, 1997a, 1997b) have posited that the distinction between conscious and unconscious processes is of questionable value if these processes do not lead to qualitatively different consequences and, indeed, have demonstrated qualitatively different effects of consciously perceived stimuli, on the one hand, and stimuli of which participants were unaware, as assessed by subjective measures of awareness, on the other hand. However, in addition to qualitatively different effects of conscious and unconscious processes, it is an interesting question whether any processes are the same with and without awareness.

The latter question was the focus of the present study, which attempted to provide empirical evidence for dissociations of priming and prime recognition owing to different time courses. The rationale of the approach was the following: If one could show that SOA affects prime recognition performance and priming effects in opposite ways, this would suggest that priming and prime recognition performance result from different processes. To associate these different processes to consciousness, we can follow the reasoning of Reingold and Merikle (1988, 1990), which was based on a single, reasonable assumption. Applied to the present study, this assumption is that the sensitivity of prime recognition to conscious information of the prime is greater than or equal to the sensitivity of the priming index. In other words, conscious information regarding primes, if it exists, should be used equally or more efficiently in the prime recognition task than in the choice RT task. Reingold and Merikle (1988) reasoned from this assumption that unconscious processing is implicated whenever priming shows greater sensitivity than prime recognition performance, given that prime recognition and priming are measured in situations that differ only in the instructions. 
The present experiments satisfied these requirements by a number of procedures. In the sessions in which the participants worked on the priming task, they were neither informed about the existence of the prime stimulus nor instructed to attend to it, but they were told to attend to the mask, and there was no obvious cost or benefit that might have motivated the participants to give information of primes any weight. In contrast, at the beginning of the final session, in which participants worked on the prime recognition task, the primes were shown to them in slow motion, they were told that primes occurred in every trial, they were instructed to attend to the primes, and they got error feedback during the experiment on every trial in which they made a recognition error, in order to motivate them to try to use any available information of the primes. Furthermore, with the exception of instruction and error feedback, every other detail of the experiment was identical in priming sessions and the prime identification session in which prime recognition was measured in a two-choice task with a sufficient number of replications. Note that regarding response metrics, priming and prime recognition performance differed in the present study. However, the double dissociation of priming and prime recognition performance in terms of opposite time courses cannot be due to differences in response metrics if both priming and prime recognition performance change significantly with SOA in opposite directions. To sum up, it is reasonable to assume that the participants were indeed more sensitive to conscious information about primes in the recognition task, as compared with the priming task.

Results showed that priming of motor and nonmotor operations increases with increases in SOA, despite the fact that performance in prime recognition decreased for at least some of the participants. Can different time courses of priming and prime recognition performance be generated from the same underlying processes? Suppose that priming effects are simply a function of the processes that also generate conscious awareness of primes and, hence, modulate prime recognition. Then, priming effects and prime recognition performance should follow similar time courses: Both should increase or decrease with increases in SOA, or one measure should at least remain unchanged, if it is insensitive to SOA. Opposite time courses, however, cannot be explained by a single mechanism. Instead, the dissociation of increasing priming effects in the face of decreasing prime recognition shows that priming effects increase owing to processes that do not depend on prime awareness.

\section{Priming Without Awareness?}

This controversy shows that understanding the empirical dissociation of the present findings regarding priming without awareness requires that we make certain assumptions. Nonetheless, several features of the present data indicate that priming of motor and nonmotor operations does not depend on conscious prime recognition. This is demonstrated by three examples, each of which requires a differ- ent assumption. (1) We might assume that performance at chance level indexes absence of all conscious information. This assumption was made in a number of studies (e.g., Dehaene et al., 1998; Klotz \& Neumann, 1999; Neumann \& Klotz, 1994; Vorberg et al., in press). In the present study, evidence for priming without awareness comes from Experiment 3 and Experiment 5, in which participants showed substantial nonmotor priming effects although they could not discriminate primes better than chance.

(2) To infer priming without awareness, we might alternatively assume that the probability of correct prime recognition over a series of 96 trials correlates positively with the degree of all consciously available information regarding the primes. When discrimination decreases from $88 \%$ to $60 \%$ correct, as in Experiment 4, we thus infer that the available conscious information decreased too. We therefore conclude that the increase in priming effects in these conditions indicate priming independent from conscious information. The same conclusion follows from the finding that time course and magnitude of priming effects were virtually identical in participants who could discriminate primes well and those who could not, as in Experiments 2 and 3.

(3) Following Reingold and Merikle (1988, 1990), we might assume that prime recognition performance is more sensitive to consciously available information than is priming. On the basis of this assumption, the double dissociation of priming and prime recognition performance by opposite time courses results because prime recognition mainly reflects conscious information, whereas priming effects increase owing to processes that do not depend on the consciousness of the effective stimulus. Taken together, these three examples show that if one is willing to accept only one of these assumptions regarding the relation between prime recognition performance and conscious awareness of primes, it has to be concluded that priming of mental operations does not depend on awareness of the effective stimuli.

\section{Location of Priming of Mental Operations}

The main point of the present work consists in showing that motor priming and nonmotor priming are comparable in several respects. Therefore, priming might be based on similar processes in every instance. An obvious communality across experiments consisted in the instruction given to the participants to use the cue for a mental operation. This appears to be important, because instructions might lead the system to adopt a specific set that is adjusted to respond to critical stimulus information without conscious perception of the effective stimulus (Neumann, 1984). In addition, the magnitude of the priming effect varied with experiments, which indicates that priming effects result from different sources in each case. At least three locations are conceivable at which prime-mask congruence could affect performance, resulting in the observed priming effects: (1) at perceptual levels, (2) at central levels of executive control, or (3) at other locations that depend on what the cue is used for. 
Note that priming might result from the effect of primemask congruency at each one of these levels alone or from some combination of effects at different levels. In what follows, I will consider each of these possibilities in turn.

(1) In each of the first four experiments in the present study, the same prime and mask stimuli followed each other with identical SOAs. Therefore, it seems plausible that comparable effects of prime-mask congruency might result from early perceptual interaction of prime and masking stimuli. The effects of early interaction of prime and mask stimuli as a function of SOA have been studied extensively by research on metacontrast masking (Breitmeyer, 1984; Francis, 1997). According to recent theory and data on metacontrast masking, visual stimuli cannot be processed further in the perceptual system when they are overwritten by newly arriving visual input before boundary contours have been computed and filled in (Francis, 1997). Therefore, the interaction of prime and mask at perceptual levels of processing is reflected in the time course of prime recognition performance. However, prime recognition performance and priming followed different time courses in the present experiments, indicating that the priming effect is not located at perceptual levels of processing. Furthermore, error rates, as well as electrophysiological evidence from studies of motor priming, indicate that primes can activate their associated responses. Taken together, it is unlikely that priming effects can be reduced entirely to prime-mask interaction at early levels of the visual system.

(2) At some point in the system, primes and masking stimuli might arrive at a level at which stimulus processing is determined by the instructions followed by the participant. Similar priming functions dissociated from prime recognition performance might have arisen in every experiment in the present study because priming results from a mechanism at a central level that is involved in every experimental task. The model put forward by Norman and Shallice (1986) might describe the central mechanism that accounts for the observed priming effects. These authors assume that actions are controlled by schemata, collections of actions that are run off automatically, given the appropriate triggering. To apply Norman and Shallice's model to the present findings, suppose that representations of schemata can be activated by visual stimulus information. When the system is prepared for specific visual information that is relevant for the present task, one could assume that these schema representations can be activated by information conveyed by both the prime and the mask. If representations of schemata accumulate stimulus information without distinguishing prime and masking stimuli, priming effects could result that increase with SOA.

However, research on motor priming has provided behavioral (Vorberg et al., in press), as well as electrophysiological, (Dehaene et al., 1998; Eimer \& Schlaghecken, 1998; Leuthold \& Kopp, 1998) data that suggest that primes can activate responses at cortical levels of the motor system. To account for priming effects at levels beyond the central level, at least two alternatives are conceivable. On the one hand, the central system might transmit signals to other processing systems, perceptual or motor. Alternatively, there might be direct links from visual processing to these other processing systems that circumvent the central level. According to the first view, triggered by primes, the central system causes the activation of mental operations. In this way, prime stimuli could indirectly cause the activation of motor responses, as measured by electrophysiological studies of motor priming. To account for priming of attention, we would have to assume that primes trigger shifting of attention to specific stimulus modalities. Activation in the visual and the auditory systems has been found in brain-imaging studies on attention (e.g., Corbetta, Miezin, Dobmeyer, Shulman, \& Petersen, 1990; Grady et al., 1997; Woodruff et al., 1996). Therefore, priming of attention can be assumed to lead also to activation of perceptual systems. To explain priming of cognitive control along these lines, we could assume that prime stimuli trigger the activation of task-set representations. Taken together, priming might be located in structures representing central levels of processing that transfer the effect of primes to different mental operations located in the motor cortex, in some experiments, and in the visual or auditory cortex, in others.

(3) Alternatively, it has been suggested, on the basis of response priming data, that primes affect levels of motor processing on a direct visuomotor pathway to the motor system (Leuthold \& Kopp, 1998; Neumann \& Klotz, 1994). Priming of attention and priming of cognitive control might similarly be located at levels beyond central processing mechanisms. According to this view, priming results from different processes that are specific for each experimental task but, nonetheless, process information according to general principles that generate similar priming effects (see Phillips, 1997). In particular, response priming effects provide evidence in favor of Neumann's (1990) assumption that sensory information affects response parameters directly, without mediation by processes if the system is set, to the extent that further processing requires only information that is also provided by the prime. Although priming of precued actions (Experiment 2) is more indirect, as compared with response priming, it might still be explained by direct effects of primes on the motor system. However, to explain priming of attention and priming of cognitive control operations along this line, it has to be assumed that nonmotor processes can be affected directly by primes too. In particular, given that the system is properly set (Neumann, 1984), primes might activate representations in the motor system in the same way as in perceptual systems or at levels of task-set representations. Suppose that primes and masking stimuli activate representations in the same way and that alternative representations compete for behavioral control. Then, priming effects increase with increases in SOA, because activation of rep- 
resentations accumulates over time, as our accumulator model suggests (Vorberg et al., in press).

The view that primes affect different representations located at different sites in motor, as compared with nonmotor, tasks is consistent with recent accounts of implicit perceptual and motor memory (e.g., Jacoby, Lindsay, \& Toth, 1992; Tulving \& Schacter, 1990; Ungerleider, 1995). According to these accounts, representations in the sensory and motor cortex are continually changed by current events and are also engaged during retrieval. These effects remain unconscious until additional structures come into play that are involved in the generation of conscious awareness. This view is backed by neuroimaging studies of implicit retrieval showing reduced activation in response to primed stimuli in visual processing areas, as well as in higher order brain regions in the left prefrontal cortex (for a review, see Buckner \& Koutstaal, 1998). To sum up, it seems most reasonable that priming effects result, at least in part, from their effects on (1) perceptual representations in priming of attention, (2) task-set representations in priming of cognitive control, and (3) motor representation in priming of motor precuing and in direct response priming tasks.

\section{Limits of Priming of Mental Operations}

What are the limits of priming of mental operations? According to the present view, participants first set mental operations consciously by implementing the instructed experimental task at the beginning of a session. Priming of mental operations can be found when the perceptual system produces an output that can be used for further processing by these properly set mental operations. For the visual system, the present findings, as well as previous research, have demonstrated that it can extract sufficient information for these effects from masked stimuli that remain outside of awareness. Similar findings are expected for other perceptual systems. Thus, after having set the system consciously, mental operations do not require continuing conscious control but can process information independently from awareness of the effective stimuli. Because operations in the perceptual system, as well as in the motor system, were affected by primes in the present study, it is expected that a wide range of mental operations should be sensitive to priming as well. Note that this view resembles an extended and liberalized version of the direct parameter specification hypothesis (see Neumann, 1984). Priming is limited, however, by temporal constraints, because preliminary research showed that priming effects decline rapidly within a few hundred milliseconds. Conscious operations might be important to maintain these shortlived effects of primes.

\section{Conclusion}

The present research demonstrates that priming of nonmotor operations is comparable to motor priming in its time course and its dissociation from prime recognition. Several features of the findings support the view that priming of mental operations does not depend on conscious awareness of the effective stimuli. Findings suggest that similar processes are involved in priming of motor and nonmotoroperations. Priming of mental operations results either from a general principle that is effective in different systems or from the operation of a single central mechanism that is involved in every experimental task, generating priming effects of masked stimuli. Functional brainimaging studies could help to clear up this open issue.

\section{REFERENCES}

Abrams, R. L., \& Greenwald, A. G. (2000). Parts outweigh the whole (word) in unconscious analysis of meaning. Psychological Science, 11, 118-124.

Allport, A., Styles, E. A., \& Hsieh, S. (1994). Shifting intentional set: Exploring the dynamic control of tasks. In C. Umiltà \& M. Moscovitch (Eds.), Attention and performance XV: Conscious and nonconscious information processing (pp. 421-452). Cambridge, MA: MIT Press.

BACHMAnN, T. (1984). The process of perceptual retouch: Nonspecific afferent activation dynamics in explaining visual masking. Perception \& Psychophysics, 35, 69-84.

BreITMEYER, B. (1984). Visual masking: An integrative approach. Oxford: Oxford University Press.

Buckner, R. L., \& Koutstaal, W. (1998). Functional neuroimaging studies of encoding, priming, and explicit memory retrieval. Proceedings of the National Academy of Sciences, 95, 891-898.

Cheesman, J., \& Merikle, P. M. (1986). Distinguishing conscious from unconscious perceptual processes. Canadian Journal of Psychology, 40, 343-367.

Corbetta, M., Miezin, F. M., Dobmeyer, S., Shulman, G. L., \& Petersen, S. E. (1990). Attentional modulation of neural processing of shape, color, and velocity in humans. Science, 248, 1556-1559.

Dehaene, S., Naccache, L., Le Clec'H, G., Koechlin, E, Müller, M., Dehaene-Lambertz, G., van de Moortele, P. F., \& Le Bihan, D. (1998). Imaging unconscious semantic priming. Nature, 395, 597-600.

Eimer, M., \& Schlaghecken,F. (1998). Effects of masked stimuli on motor activation: Behavioral and electrophysiological evidence. Journal of Experimental Psychology: Human Perception \& Performance, 24, 1737-1747.

ERIKSEN, C. W. (1960). Discrimination and learning without awareness: A methodological survey and evaluation. Psychological Review, 67, 279-300.

Fehrer, E., \& RAAB, D. (1962). Reaction time to stimuli masked by metacontrast. Journal of Experimental Psychology, 63, 143-147.

FrancIS, G. (1997). Cortical dynamics of lateral inhibition: Metacontrast masking. Psychological Review, 104, 572-594.

Grady, C. L., Van Meter, J. W., Maisog, J. M., Pietrini, P., KraSUSKI, J., \& RAUSChecker, J. P. (1997). Attention-related modulation of activity in primary and secondary auditory cortex. NeuroReport, 8, 2511-2516.

Greenwald, A. G. (1992). Unconscious cognition reclaimed. American Psychologist, 47, 766-779.

Greenwald, A. G., Draine,S. C., \& Abrams, R. L. (1996). Three cognitive markers of unconscious semantic activation. Science, 273, 1699-1702.

Holender, D. (1986). Semantic activation without conscious identification in dichotic listening, parafoveal vision, and visual masking: A survey and appraisal. Behavioral \& Brain Sciences, 9, 1-66.

JAcoby, L. L., LindSAy, D. S., \& Toth, J. P. (1992). Unconscious influences revealed. American Psychologist, 47, 802-809.

JENSEN, A. R. (1996). The $g$ factor. Nature, 381, 729.

KeELe, S. W. (1981). Behavioral analysis of movement. In V. B. Brooks (Ed.), Handbook of physiology: Section 1. Vol. 2: Motor control (pp. 1391-1414). Bethesda, MD: American Physiological Society.

Klinger, M. R., Burton, P. C., \& Pitts, G. S. (2000). Mechanisms of unconscious priming: I. Response competition, not spreading activation. Journal of Experimental Psychology: Learning, Memory, \& Cognition, 26, 441-455.

Klotz, W., \& Neumann, O. (1999). Motor activation without con- 
scious discrimination in metacontrast masking. Journal of Experimental Psychology: Human Perception \& Performance, 25, 976-992.

KöHLER, S., \& Moscovitch, M. (1997). Unconscious visual processing in neuropsychological syndromes: A survey of the literature and evaluation of models of consciousness. In M. Rugg (Ed.), Cognitive neuroscience (pp. 305-375). Hove, U.K.: Psychology Press.

Leuthold, H., \& KopP, B. (1998). Mechanisms of priming by masked stimuli: Inferences from event-related potentials. Psychological Science, 9, 263-269.

Leuthold, H., Sommer, W., \& Ulrich, R. (1996). Partial advance information and response preparation: Inferences from the lateralized readiness potential. Journal of Experimental Psychology: General, 125, 307-323.

Macmillan, N. A., \& Creelman, C. D. (1991). Detection theory: A user's guide. New York: Cambridge University Press.

Merikle, P. M. (1992). Perception without awareness. American Psychologist, 47, 792-795.

Merikle,P. M., \& Daneman, M. (1998). Psychological investigation of unconscious perception. Journal of Consciousness Studies, 5, 5-18.

Merikle, P. M., \& Joordens, S. (1997a). Measuring unconscious influences. In J. D. Cohen \& J. W. Schooler (Eds.), Scientific approaches to consciousness (pp. 109-123). Mahwah, NJ: Erlbaum.

MerikLe, P. M., \& Joordens, S. (1997b). Parallels between perception without attention and perception without awareness. Consciousness \& Cognition, 6, 219-236.

MiLleR, J. O. (1982). Discrete versus continuous stage models of human information processing: In search of partial output. Journal of Experimental Psychology: Human Perception \& Performance, 8, 273-296.

Milner, A. D., \& Goodale, M. A. (1995). The visual brain in action. Oxford: Oxford University Press.

Monsell, S. (1996). Control of mental processes. In V. Bruce (Ed.), Unsolved mysteries of the mind (pp. 93-148). Hove, U.K.: Erlbaum.

NaCCACHe, L., \& DehaEne, S. (2001a). The priming method: Imaging unconscious repetition priming reveals an abstract representation of number in the parietal lobes. Cerebral Cortex, 11, 966-974.

Naccache, L., \& Dehaene, S. (2001b). Unconscious semantic priming extends to novel unseen stimuli. Cognition, 80, 215-229.

Neumann, O. (1984). Automatic processing: A review of recent findings and a plea for an old theory. In W. Prinz \& A. F. Sanders (Eds.), Cognition and motor processes (pp. 255-293). Berlin: Springer-Verlag.

Neumann, O. (1990). Direct parameter specification and the concept of perception. Psychological Research, 52, 207-215.

Neumann, O., \& KLotz, W. (1994). Motor responses to nonreportable masked stimuli: Where is the limit of direct parameter specification? In C. Umiltà, \& M. Moscovitch (Eds.), Attention and performance $X V$ : Conscious and nonconscious information processing (pp. 124150). Cambridge, MA: MIT Press.

Norman, D. A., \& Shallice, T. (1986). Attention to action: Willed and automatic control of behavior. In R. J. Davidson, G. E. Schwartz, \& D. Shapiro (Eds.), Consciousness and self-regulation (pp. 1-18). New York: Plenum.

PASHLER, H. E. (1998). The psychology of attention. Cambridge, MA: MIT Press.

Phillips, W. A. (1997). Theories of cortical computation. In M. D. Rugg (Ed.), Cognitive Neuroscience (pp. 11-46). Cambridge, MA: MIT Press.

RAMACHANDRAN, V. S., \& CobB, S. (1995). Visual attention modulates metacontrast masking. Nature, 373, 66-68.

Reingold, E. M., \& Merikle, P. M. (1988). Using direct and indirect measures to study perception without awareness. Perception \& Psychophysics, 44, 563-575.

Reingold, E. M., \& Merikle, P. M. (1990). On the inter-relatedness of theory and measurement in the study of unconscious processes. Mind \& Language, 5, 9-28.

Requin, J., Brener, J., \& Ring, C. (1991). Preparation for action. In J. R. Jennings \& M. G. H. Coles (Eds), Handbook of cognitive psychophysiology: Central and autonomic nervous system approaches (pp. 357-448). Chichester, U.K.: Wiley.

Rogers, R. D., \& Monsell, S. M. (1995). Costs of a predictable switch between simple cognitive tasks. Journal of Experimental Psychology: General, 124, 207-231.
Rosenbaum, D. A. (1980). Human movement initiation: Specification of arm, direction, and extent. Journal of Experimental Psychology: General, 109, 444-474.

Shiffrin, R. M., \& SchneIder, W. (1977). Controlled and automatic human information processing: II. Perceptual learning, automatic attending and a general theory. Psychological Review, 84, 127-190.

Spence, C., \& DrIver, J. (1997). On measuring selective attention to an expected sensory modality. Perception \& Psychophysics, 59, 389-403.

Thomas, E. A. C., \& Ross, B. H. (1980). On appropriate procedures for combining probability distributions within the same family. Journal of Mathematical Psychology, 21, 136-152.

Tulving, E., \& Schacter, D. L. (1990). Priming and human memory system. Science, 247, 301-306.

UNGERLEIDER,L. G. (1995). Functional brain imaging studies of cortical mechanisms for memory. Science, 270, 769-775.

Vorberg, D., Mattler, U., Heinecke, A., Schmidt, T., \& Schwarz$\mathrm{BACH}, \mathrm{J}$. (in press). Invariant time-course of priming with and without awareness. In C. Kaernbach, E. Schröger, \& H. Müller (Eds.), Psychophysics beyond sensation: Laws and invariants of human cognition. Hillsdale, NJ: Erlbaum.

Wentura, D. (2000). Dissociative affective and associative priming effects in the lexical decision task: Yes versus no responses to word targets reveal evaluative judgment tendencies. Journal of Experimental Psychology: Learning, Memory, \& Cognition, 26, 456-469.

WolfF, P. (1989, April). Einfluss des maskierten Testreizes auf die Wahlreaktion aufden Maskierreiz bei Metakontrast [Effect of masked stimulus on choice response to the masking stimulus in metacontrast]. Paper presented at the 31st Tagung experimentell arbeitender Psychologen, Bamberg, Germany.

Woodruff, P. W., Benson, R. R., Bandettini, P. A., Kwong, K. K., Howard, R. J., Talavage, T., Belliveau, J., \& Rosen, B. R. (1996). Modulation of auditory and visual cortex by selective attention is modality-dependent. NeuroReport, 12, 1909-1913.

Yellott, J. I., JR. (1971). Correction for fast guessing and the speed-accuracy tradeoff in choice reaction time. Journal of Mathematical Psychology, 8, 159-199.

\section{NOTES}

1. Prime discrimination was measured in the first four experiments with a rating procedure. Using the computer keyboard turned around $180^{\circ}$, the participants pressed one of the three keys on the right (F1, F2, or F3) to indicate that the prime was a square (certain, very likely, probably) and one of the three left-most keys to indicate that the prime was diamond shaped. Owing to the small number of trials per condition, the analysis of the discrimination data for left- and right-hand responses was based on the data collapsed over the three keys.

2 . Note that target modality (visual or auditory) did not interact with congruency $[F(1,5)=3.0, p=.14]$ or with the SOA $\times$ congruency interaction $[F(5,25)=1.0, p=.41]$.

3. In contrast to other experiments in the literature, prime recognition performance in Experiment 5 was above chance in 4 participants, although stimulus conditions were similar. Several procedural differences from previous experiments might be responsible for this difference. On the one hand, the present experiment attempted to optimize conditions for learning how to use any feature of the prime-mask sequence for correct responses in the prime recognition session. This included clear task instructions, slow motion demonstrations of the interaction of prime and mask stimuli with successively decreasing SOA, feedback on every trial, a training block, and a large number of trials allowing the participants to develop strategies of how to use small perceptual differences to find the correct response (see Klotz \& Neumann, 1999). On the other hand, prime recognition performance was measured with the same discrimination task as that in the RT session. This discrimination task leads to higher sensitivity measures, as compared with yes-no prime detection tasks (Macmillan \& Creelman, 1991). Each of these factors potentially enlarged sensitivity in the present experiment, as compared with some previous experiments, and strengthens the finding of $d^{\prime}=0$ in 7 participants.

(Manuscript received August 21,2001; revision accepted for publication May 10, 2002.) 